BNL-107653-2014-I R

\title{
Summary Report of the Workshop on The Experimental Nuclear Reaction Data Database
}

\author{
IAEA Headquarters, Vienna, Austria \\ 6-10 October 2014
}

\author{
V.Semkova $^{1}$, B.Pritychenko ${ }^{2}$ \\ ${ }^{1}$ IAEA Nuclear Data Section, Vienna, Austria \\ ${ }^{2}$ Brookhaven National Laboratory, Upton, New York
}

December 2014

\author{
National Nuclear Data Center \\ Brookhaven National \\ Laboratory \\ P.O. Box 5000 \\ Upton, NY 11973-5000 \\ www.nndc.bnl.gov
}

U.S. Department of Energy

Office of Science, Office of Nuclear Physics

\footnotetext{
Notice: This manuscript has been authored by employees of Brookhaven Science Associates, LLC under Contract No. DE-SC0012704 with the U.S. Department of Energy. The publisher by accepting the manuscript for publication acknowledges that the United States Government retains a non-exclusive, paid-up, irrevocable, world-wide license to publish or reproduce the published form of this manuscript, or allow others to do so, for United States Government purposes.
} 


\section{DISCLAIMER}

This report was prepared as an account of work sponsored by an agency of the United States Government. Neither the United States Government nor any agency thereof, nor any of their employees, nor any of their contractors, subcontractors, or their employees, makes any warranty, express or implied, or assumes any legal liability or responsibility for the accuracy, completeness, or any third party's use or the results of such use of any information, apparatus, product, or process disclosed, or represents that its use would not infringe privately owned rights. Reference herein to any specific commercial product, process, or service by trade name, trademark, manufacturer, or otherwise, does not necessarily constitute or imply its endorsement, recommendation, or favoring by the United States Government or any agency thereof or its contractors or subcontractors. The views and opinions of authors expressed herein do not necessarily state or reflect those of the United States Government or any agency thereof. 
INDC(NDS)-0672

Distr. G+NC

International Atomic Energy Agency

\title{
INDC International Nuclear Data Committee
}

\author{
Summary Report of the Workshop on
}

\section{The Experimental Nuclear Reaction Data Database}

IAEA Headquarters, Vienna, Austria 6 - 10 October 2014

Prepared by

V. Semkova

IAEA Nuclear Data Section, Vienna, Austria

B. Pritychenko

BNL National Nuclear Data Center, Upton NY, USA

December 2014 
Selected INDC documents may be downloaded in electronic form from http://www-nds.iaea.org/publications

or sent as an e-mail attachment.

Requests for hardcopy or e-mail transmittal should be directed to

NDS.Contact-Point@iaea.org

or to:

Nuclear Data Section

International Atomic Energy Agency

Vienna International Centre

PO Box 100

1400 Vienna

Austria

Printed by the IAEA in Austria

December 2014 
INDC(NDS)-0672

Distr. G+NC

\title{
Summary Report of the Workshop on
}

\section{The Experimental Nuclear Reaction Data \\ Database}

IAEA Headquarters, Vienna, Austria

6 - 10 October 2014

\author{
V. Semkova \\ IAEA Nuclear Data Section, Vienna, Austria \\ B. Pritychenko \\ BNL National Nuclear Data Center, Upton NY, USA
}

\begin{abstract}
The Workshop on the Experimental Nuclear Reaction Data Database (EXFOR) was held at IAEA Headquarters in Vienna from 6 to 10 October 2014. The workshop was organized to discuss various aspects of the EXFOR compilation process including compilation rules, different techniques for nuclear reaction data measurements, software developments, etc. A summary of the presentations and discussions that took place during the workshop is reported here.
\end{abstract}





\section{TABLE OF CONTENTS}

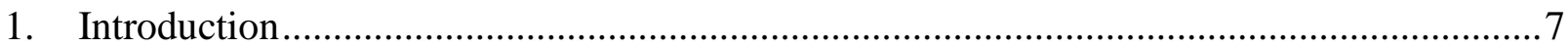

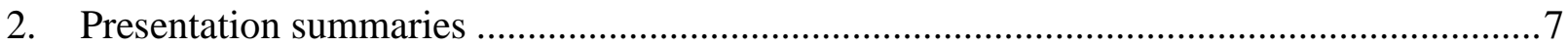

2.1. Technical remarks on compilation, N. Otuka .................................................... 7

2.2. Compilation of beta-delayed neutron emission data, V. Semkova .............................9

2.3. Results of the ${ }^{100} \mathrm{Mo}(\mathrm{p}, 2 \mathrm{n})^{99 \mathrm{~m}} \mathrm{Tc}$ cross section measurements and possible

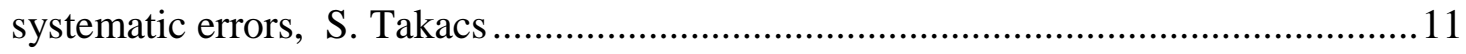

2.4. Definitions of yields. Problems and confusions, S. Takacs ..................................... 14

2.5. Neutron Kerma factors in EXFOR: actual status and missing published results,

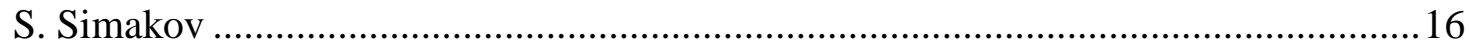

2.6. Some problems of photonuclear data compilation and evaluation, V. Varlamov ........19

2.7. Compilation of neutron data in the resolved resonance region measured by TOF method. Spectrometers' response function, V. Semkova

2.8. Neutron source spectra format. EXFOR formats and rules: present status and proposals for neutron source data storage, O. Gritzay

2.9. Nuclear astrophysics data. Calculations of nuclear astrophysics and californium neutron cross section uncertainties using ENDF/B-VII.1, JEFF-3.1.2, JENDL-4.0 and low-fidelity covariances, B. Pritychenko

2.10. Structure of software on graphic data processing for the EXFOR data library, G. Pikulina, S.Taova, S. Dunaeva.

2.11. Introduction to the digitization software GDgraph, Guochang Chen (Yongli Jin, Jimin Wang, CNDC, China).

2.12. Status of the compiled Neutron Spectra in EXFOR. Summary of discussions held at the Workshop and further developments, S. Simakov, N. Otuka, V. Semkova, V. Zerkin33

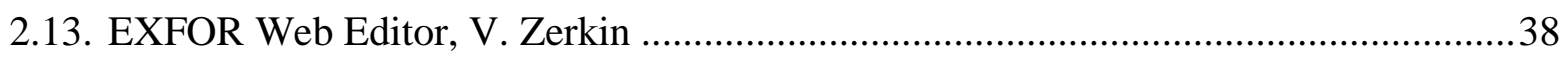

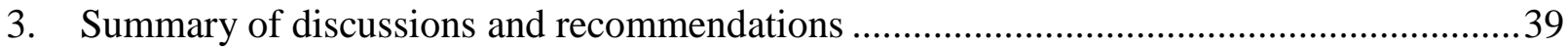

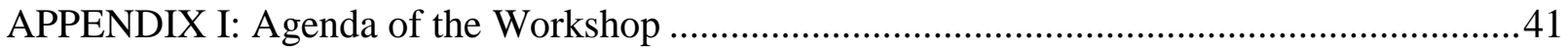

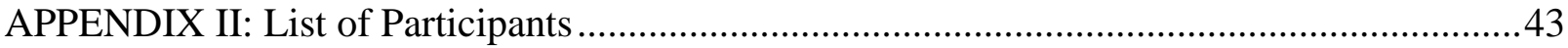




\section{THE INTERNATIONAL NETWORK OF NUCLEAR REACTION DATA CENTRES}

National, regional and specialized nuclear reaction data centres, coordinated by the International Atomic Energy Agency, cooperate in the compilation, exchange and dissemination of nuclear reaction data in order to meet the requirements of nuclear data users in all countries. At present, the following data centres participate in the International Network of Nuclear Reaction Data Centres (NRDC):

NNDC US National Nuclear Data Center, Brookhaven National Laboratory, Upton, USA

NEA DB OECD NEA Data Bank, Issy-les-Moulineaux, France

NDS IAEA Nuclear Data Section, Vienna, Austria

CJD Russian Nuclear Data Centre, Institute of Physics and Power Engineering, Obninsk, Russia

CNDC China Nuclear Data Centre, China Institute of Atomic Energy, Beijing, China

ATOMKI Charged-Particle Nuclear Reaction Data Group, Institute for Nuclear Research (ATOMKI), Debrecen, Hungary

NDPCI Nuclear Data Physics Centre of India, Bhabha Atomic Research Centre, Trombay, Mumbai, India

JAEA/NDC Nuclear Data Center, Japan Atomic Energy Agency, Tokai-mura, Japan

JCPRG Nuclear Reaction Data Centre, Hokkaido University, Sapporo, Japan

KNDC Nuclear Data Center, Korea Atomic Energy Research Institute, Daejeon, Republic of Korea

CDFE Centre for Photonuclear Experiments Data, Moscow State University, Moscow, Russia

CNPD Centre of Nuclear Physics Data, Institute of Nuclear and Radiation Physics, Russian Federal Nuclear Center -All-Russia Research Institute of Experimental Physics, Sarov, Russia

UkrNDC Ukrainian Nuclear Data Centre, Institute for Nuclear Research, Kyiv, Ukraine 


\section{Introduction}

The Workshop on The Experimental Nuclear Reaction Data Database (EXFOR) was held at IAEA Headquarters, Vienna, Austria from 6 to 10 October 2014. Eleven participants from different Nuclear Reaction Data Centres and four staff from the IAEA attended the Workshop (Appendix II)

The Workshop was organized to discuss various aspects of the EXFOR compilation process including compilation rules, different techniques for nuclear reaction data measurements, software developments, etc. At the beginning the conclusions and the recommendations of the Report NEA/DB/DOC(2014)3 "Statistical verification and validation of the EXFOR database: $(n, n),(n, 2 n),(n, p),(n, \alpha)$ and other neutron-induced threshold reaction cross sections" were discussed. Presentations of charged-particle induced reaction cross sections, thick target yields, nuclear astrophysics data, TOF spectra in the resolved resonance region, beta-delayed neutron emission data and photonuclear data measurements provided information on the experimental technique in order to improve the quality of the EXFOR compilations. The need to compile the neutron Kerma factors, status of Kerma factors in EXFOR data library and a list of articles for compilation were discussed during the Workshop. The importance of defining the format (rules) for the compilation of neutron source spectra in EXFOR was emphasized and different proposals were discussed. Software developments related to EXFOR compilation, both stand-alone and online, were presented. In addition to discussions, several compilation and digitization exercises were carried out. The Workshop was concluded with a list of recommendations.

In the welcome address S. Simakov (IAEA) and R. Capote-Noy (IAEA) greeted participants of the Workshop on behalf of the Nuclear Data Section and its Section Head, Robin Forrest, who was not able to attend.

N. Otuka was elected Chairperson of the Workshop and B. Pritychenko Rapporteur. The agenda was discussed and adopted (see Appendix I).

During the Workshop participants gave presentations, led intensive discussions and carried out compilation exercises. The presentations and Working Papers are available at https://wwwnds.iaea.org/nrdc/wksp_2014/.

The Nuclear Data Section acknowledged all participants for their cooperation and contribution to this Workshop.

\section{Presentation summaries}

\subsection{Technical remarks on compilation, N. Otuka}

Technical remarks from the reviewers were discussed. Many of them are treated as recommendations rather than (proposals of) new rules. Some of them could be further discussed and added to the manuals if appropriate. The goal is to make key information more visible in a simple and concise EXFOR database.

\section{DECAY-DATA - $\mathbf{T}_{1 / 2}$ vs isomeric flag}

All half-lives coded under the keyword DECAY-DATA with those compiled in the Nuclear Wallet Cards were compared last year, and a list was prepared for cases where more than $50 \%$ deviation exists between EXFOR and Nuclear Wallet Cards. Each case was checked with Svetlana Babykina against the source article as well as the ENSDF library (mainly through the LiveChart of Nuclides). Some cases are for straight forward corrections, e.g., simple mistake by the compiler, change in the level order (e.g., 5 $\mathrm{hr}$ and $70 \mathrm{~min}$ state of $\left.{ }^{120} \mathrm{In}\right)$. But our response must be discussed for some non-trivial cases (e.g., half- 
life reported by the author but without a corresponding state in ENSDF, isomeric flag for which its level ordering is uncertain (e.g., the $17 \mathrm{sec}$ and 6 min state of $\left.{ }^{108} \mathrm{Rh}\right)$.

\section{Level energies in heavy-ion binary reactions}

The level energy ( $\mathrm{E}-\mathrm{LVL}$ ) of the residual nucleus (reaction product) is sufficient to characterize the secondary energy of the binary reaction when the projectile is a light particle (e.g., neutron, proton, deuteron). However, both the outgoing nucleus and residual nucleus may not be in their ground states. Therefore, the compiler should provide the level energies of both products (e.g., under E-LVL1 and ELVL2) when a partial data set is compiled for a binary heavy-ion induced reaction.

\section{Alternative (interdependent) results}

Different results for the same quantity obtained in the same experiment by two different methods of analysis (e.g., two data sets obtained by off- and on-line analysis, two data sets from two flight paths.) may be coded in the (1) same subentry by using the multiple reaction formalism, or (2) separated subentries linked to each other by COREL under the keyword STATUS. However, the flags should not be used for this purpose. Also two entries must be linked to each other not by COREL but by a related reference $(\mathrm{REL}-\mathrm{REF})$ type $\mathrm{O}$ when they are compiled from the same article (e.g., neutron data in area 1 while charged-particle in area $\mathrm{C}$ ).

\section{Keywords kept in deleted entries}

Our current rule asks to keep REFERENCE, TITLE, AUTHOR, INSTITUTE, and HISTORY keywords in the common subentry (001) when an entry is deleted, while the decision is up to the compiler for other keywords. In order to make future maintenance of deleted entries easier (e.g., replacement of a code due to dictionary update), it is recommended to delete unnecessary keywords.

\section{Free text - Be short and concise!}

The compiler should not perform a simple "copy and paste" operation but rather carefully identify essential key information to be kept as free text. Lengthy free text information may hide the essential free text information. Repetition of the coded information by its expansion in free text should be avoided. A coded form should be adopted instead of free text when possible. When appropriate, free text must be entered under the keyword and code to which it pertains.

\section{Source described under ERR-ANALYS}

The EXFOR Formats Manual introduces the keyword ERR-ANALYS as follows: "Explains the sources of uncertainties and the values given in the COMMON or DATA". The "source" in this sentence does not mean where the compiler found the uncertainties but what types of error sources are considered (e.g., counting statistics, normalization). Therefore, headings should not be trivialized as "The uncertainty is reported by authors on figure". Some headings (e.g., ERR-DIG) are self-explanatory without any free text information, and it is advisable not to define such headings under this keyword.

\section{Documentation of alterations under HISTORY}

In the NRDC 2014 meeting documents, the conclusion was that (1) all important alterations must be described in each affected data subentry in addition to a short summary (e.g., subentry numbers) in the common (001) subentry; (2) compilers will not be urged to document all changes under HISTORY (c.f. Conclusion 28 and Action 12 of the meeting). It is proposed that the documentation of formal corrections (e.g., upper to lower cases, two digits to four digits year) should be avoided in favour of the more important alterations. 


\subsection{Compilation of beta-delayed neutron emission data, V. Semkova}

The main characteristics of the beta-delay neutron emission, the measurement techniques and the compilation rules were discussed in accordance with the decision of the NRDC Meeting 2014 to include beta-delayed neutron spectra from specific precursors in the scope of the EXFOR compilation. The rules for the compilation of the emission probabilities have been revised in order to take into account the probability of the emission of more than one beta-delayed neutron from a precursor.

Beta-delayed neutron emission data are important in many fields of science and applications. Regarding nuclear technologies, beta-delayed neutron are essential for reactor kinetics, safety and decay heat analysis. The new developments of advanced reactors, Accelerator Driven Systems etc., considerably extend: the type of the targets; projectiles and excitation energies involved in the nuclear fission or fragmentation processes; the composition of the fission products and its dynamics during the fuel cycle. In such cases the calculations of the aggregate beta-delayed neutron characteristics based on the data for the individual precursors are more feasible than the measurements. The benchmark experiments are particularly sensitive to a beta-delayed neutron emission. In such experiments $\beta_{\text {eff }}$ is used as a conversion factor between experimental results and calculations, which implies a high accuracy of the beta-delayed neutron emission data. The beta-delayed neutron emission is an important process for nuclear astrophysics. The process may shift the decay path towards lower masses. It also provides neutrons during the freeze-out stage. There is a renewed interest in the beta-delayed neutron data measurements in recent years. Consistent compilation of the beta-delayed neutron emission data measurements will provide an experimental data record in this field.

The compilers are advised to verify the $\left(\mathrm{Q}_{\beta}>\mathrm{S}_{\mathrm{Nn}}\right)$ condition for emission of beta-delayed neutrons during the compilation. This condition can be calculated using atomic masses of the isotopes involved. Such data are also available, for example, from the Live Chart of Nuclides (https://wwwnds.iaea.org/relnsd/vcharthtml/VChartHTML.html). The decay of a precursor may be followed by a decay chain as presented in Fig. 1 [1]. Thus, the decay of some precursors can be followed by the emission of more than one beta-delayed neutron. The coding rules for the compilation of beta-delayed neutron emission from the specific precursor Z-S-A are defined in $\underline{\text { Memo CP-C/429 }}$ as follows:

- The delayed neutron emission probability (= probability for emission of at least one beta-delayed neutron), $\mathrm{P}_{\mathrm{n}}$, is coded as: ,PN with units NO-DIM.

- The probability of emission of $\mathrm{N}$ beta-delayed neutrons, $\mathrm{P}_{\mathrm{Nn}}$, is coded as: ,NUM,PN with units NODIM.

- The delayed-neutron emission multiplicity, $\langle\mathrm{n}\rangle=\mathrm{P}_{1 \mathrm{n}}+2^{*} \mathrm{P}_{2 \mathrm{n}}+3^{*} \mathrm{P}_{3 \mathrm{n}}+\ldots$ is coded as ,MLT,DN with units PRT/DECAY or PC/DECAY.

- The energy spectrum of delayed neutrons emitted by a specific precursor is coded as: ,PN/DE with units of dimension $1 / \mathrm{E}$.

The precursors' production and separation methods applied at different experimental facilities are shown in Table 1. The following new codes for the keyword METHOD have been proposed in the WP2014- 23(Rev.) NIFIS (neutron induced fission), PIFIS(proton induced fission), HIIFR (heavy-ion induced fragmentation), LIISP (light-ion-induced spallation $\mathrm{LCP}<=4$ ) documents. 


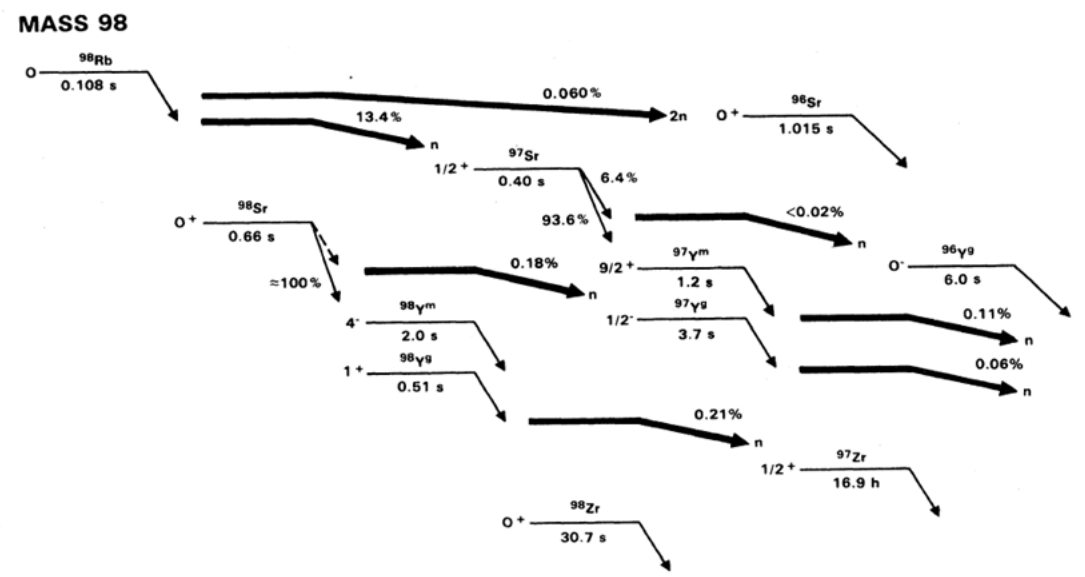

Fig.1. The mass chain beginning with ${ }^{98} \mathrm{Rb}$ and delayed-neutron branching ratios from the Ref. [1].

Determination of the branching ratios and decay characteristics is often performed by analysis of the measured growth and decay curves as presented in Fig. 2 [1].
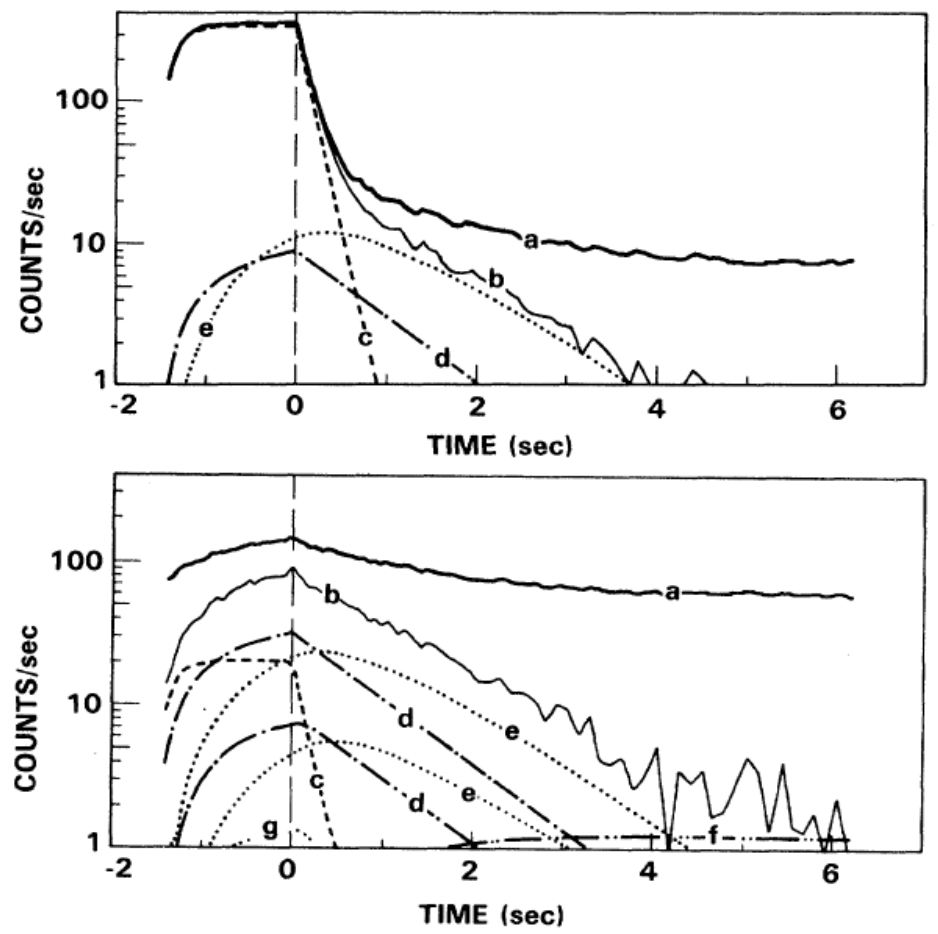

FIG. 4. Growth and decay curves at mass 98 and calculated components; the upper for the neutron, the lower for the beta. $a$ denotes the experimental count rate. $b$ denotes the count rate after subtraction of constant background. $c$ denotes ${ }^{98} \mathrm{Rb}(0.108$ s). $d$ denotes ${ }^{98} \mathrm{Sr}(0.66 \mathrm{~s}) . e$ denotes ${ }^{98} \mathrm{Y}^{8}(0.51 \mathrm{~s}) . f$ denotes ${ }^{98} \mathrm{Zr}$ (30.7 s). $g$ denotes ${ }^{97} \mathrm{Sr}(0.40 \mathrm{~s})$. For the beta curve, ${ }^{98} \mathrm{Sr}$ and

Fig. 2 Growth and decay curves from Ref. [1] 
Table 1. Production and separation methods of beta-delayed neutron precursors at different experimental facilities.

\begin{tabular}{|c|c|c|c|}
\hline Facility & $\begin{array}{l}b d n \text { precursors } \\
\text { production reaction }\end{array}$ & precursors separation method & $\begin{array}{l}\text { Compilation } \\
\text { Codes }\end{array}$ \\
\hline ILL Grenoble France & $\mathrm{n}_{\mathrm{th}}+{ }^{\mathrm{nat}} \mathrm{U}$ & LOHENGRIN recoil mass separator & NIFIS \\
\hline Univ. Mainz, Germany & $\mathrm{n}_{\mathrm{th}}+{ }^{\mathrm{nat}} \mathrm{U}$ & Chemical separation. techniques & \\
\hline Studsvik, Sweden & $\mathrm{n}_{\mathrm{th}}+{ }^{\mathrm{nat}} \mathrm{U}$ & OSIRIS isotope separator & \\
\hline $\begin{array}{l}\text { HFBR, Brookhaven Nat. } \\
\text { Lab., USA }\end{array}$ & $\begin{array}{l}\mathrm{n}\left({ }^{56} \mathrm{Fe} / \mathrm{Al} \text { and } \mathrm{Sc} / \mathrm{Ti}\right. \\
\text { filtered beam })+{ }^{\text {nat }} \mathrm{U}\end{array}$ & TRISTAN mass separator. & \\
\hline CERN & $\mathrm{p}(1 \mathrm{GeV})+{ }^{\text {nat }} \mathrm{U}$ & ISOLDE On-line mass sep & PIFIS \\
\hline GSI, Germany & ${ }^{238} \mathrm{U}(1 \mathrm{GeV} / \mathrm{u})+\mathrm{Be}$ & $\begin{array}{l}\text { FRB Fragment separator }+ \\
(\mathrm{TOF}+\mathrm{dE}) \text { isotope identification }\end{array}$ & HIIFR \\
\hline $\begin{array}{l}\text { Holyfield Radioactive Ion } \\
\text { Beam Facility (HRIBF) } \\
\text { Oak Ridge Net. Lab., } \\
\text { USA }\end{array}$ & $\mathrm{p}(50 \mathrm{MeV})+{ }^{\text {nat }} \mathrm{U}$ & $\begin{array}{l}\text { IRIS-1 + IRIS2 + selective laser } \\
\text { ionization }\end{array}$ & PIFIS \\
\hline $\begin{array}{l}\text { Cyclotron Lab. Of Univ. } \\
\text { of Jyvaskyla }\end{array}$ & $\mathrm{p}(25 \mathrm{MeV})+\mathrm{Th}$ & Mass separator + penning trap & PIFIS \\
\hline RIPS at RIKEN & ${ }^{40} \mathrm{Ar}+{ }^{\text {nat }} \mathrm{Ta}$ & $\begin{array}{l}\text { Fragment separator }+ \\
(\mathrm{TOF}+\mathrm{dE}) \text { isotope identification }\end{array}$ & HIIFR \\
\hline TRIUMF & $p(25 \mathrm{MeV})+{ }^{238} \mathrm{U}$ & Mass separator + Isobar separator & \\
\hline
\end{tabular}

Many complex detection systems have been developed recently for the simultaneous or coincidence detection of the beta particles, neutrons, gamma rays. Improved detection and acquisition systems have been developed for beta-delayed neutron measurements. A new technique for precise studies of betadecay using a linear radiofrequency-quadrupole ion trap is described in Ref. [2]. The recoil nucleus and the emitted particles from the radioactive decay have sufficient energy to leave the volume of the trap. After that the charged particles are guided by associated spectrometer systems towards detectors. The kinematics of the process is determined using conservation of energy and momentum.

References:

[1] P.L. Reeder and R.A. Warner, Phys. Rev C28 (1983) 1740.

[2] N.D. Scielzo et al., Nuclear Instruments and Methods Phys. Res., A681 (2012) 94.

\subsection{Results of the ${ }^{100} \mathrm{Mo}(\mathrm{p}, 2 \mathrm{n}){ }^{99 \mathrm{~m}} \mathrm{Tc}$ cross section measurements and possible systematic errors, S. Takacs}

The nuclear medicine community is expressing concerns regarding potential shortages of ${ }^{99 \mathrm{~m}} \mathrm{Tc}$ supply based on the fission production of ${ }^{99} \mathrm{Mo}$ from highly-enriched uranium (HEU) to prepare ${ }^{99} \mathrm{Mo} /{ }^{99 \mathrm{~m}} \mathrm{Tc}$ generators. As an alternative to a reactor-produced ${ }^{99} \mathrm{Mo} /{ }^{99 \mathrm{~m}} \mathrm{Tc}$ generator technology, the direct accelerator production of ${ }^{99 \mathrm{~m}} \mathrm{Tc}$ is considered. However, the most of the available experimental cross section data for ${ }^{100} \mathrm{Mo}(\mathrm{p}, 2 \mathrm{n}){ }^{99 \mathrm{~m}} \mathrm{Tc}$ reaction have the same general shape while their amplitudes are different. A large difference of more than a factor of two exists between the lowest and highest datasets. 
There are several error sources that could contribute to the differences among the reported datasets:

- Beam current

- Target thickness

- Detector efficiency

- Nuclear decay data

- Problematic peak analysis

- Latent cooling time error

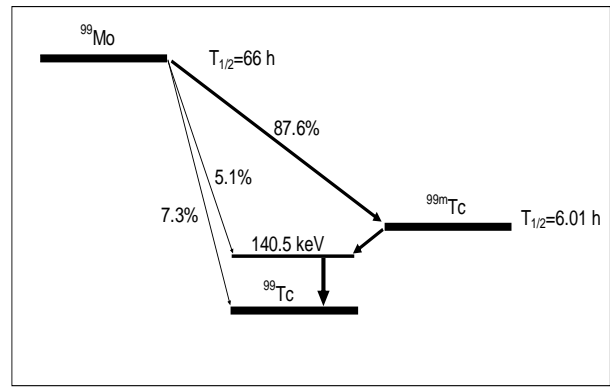

Figure 1. Simplified decay scheme of ${ }^{99} \mathrm{Mo}$

The most important and most probable error sources are the obsolete nuclear decay data and the data evaluation methods.

The aim of this study was to determine the absolute amplitude of the excitation function of ${ }^{100} \mathrm{Mo}(\mathrm{p}, 2 \mathrm{n}){ }^{99 \mathrm{~m}} \mathrm{Tc}$ reaction. For determining of the cross section peaks in spectra the $\mathrm{E}_{\gamma}=140.5 \mathrm{keV}$ gamma photons could be used.

The $\mathrm{E}_{\gamma}=140.5 \mathrm{keV}$ gamma photons have four different origins, these are:

- Decay of directly-produced ${ }^{99 \mathrm{~m}} \mathrm{Tc}$ (Eq.1)

- Decay of ${ }^{99 \mathrm{~m}} \mathrm{Tc}$ produced during extensive irradiation by decay of ${ }^{99} \mathrm{Mo}$ (Eq.2)

- Decay of ${ }^{99 \mathrm{~m}} \mathrm{Tc}$ produced after end of bombardment (EOB) by decay of ${ }^{99} \mathrm{Mo}$ (Eq.3)

- Prompt gamma radiation that follows the decay of ${ }^{99} \mathrm{Mo}$ (Eq.4)

The corresponding contributions to the total peak area $T_{\gamma}$ acquired during a $t_{m}$ measuring time after a $t_{b}$ irradiation and $t_{c}$ cooling time for a given Mo target foil can be described by the following four equations for the above four components respectively.

$$
\begin{aligned}
& T_{\gamma}(\text { direct })_{D}=\varepsilon_{d} \varepsilon_{\gamma_{2}} \varepsilon_{t} N_{t} N_{b} \sigma_{2}\left(1-e^{-\lambda_{2} t_{b}}\right) \frac{1}{\lambda_{2}} e^{-\lambda_{2} t_{c}}\left(1-e^{-\lambda_{2} t_{m}}\right) \\
& T_{\gamma}(\text { decay })_{x}=\varepsilon_{d} \varepsilon_{\gamma_{2}} \varepsilon_{t} \frac{f N_{t} N_{b} \sigma_{1}}{\left(\lambda_{1}-\lambda_{2}\right)}\left[\lambda_{1}\left(1-e^{-\lambda_{2} t_{b}}\right)-\lambda_{2}\left(1-e^{-\lambda_{1} t_{b}}\right)\right] \frac{1}{\lambda_{2}} e^{-\lambda_{2} t_{c}}\left(1-e^{-\lambda_{2} t_{m}}\right) \\
& T_{\gamma}(\text { decay })_{y}=\varepsilon_{d} \varepsilon_{\gamma_{2}} \varepsilon_{t} \frac{f N_{t} N_{b} \sigma_{1}}{\left(\lambda_{1}-\lambda_{2}\right)}\left(1-e^{-\lambda_{1} t_{b}}\right)\left[e^{-\lambda_{2} t_{c}}\left(1-e^{-\lambda_{2} t_{m}}\right)-\frac{\lambda_{2}}{\lambda_{1}} e^{-\lambda_{1} t_{c}}\left(1-e^{-\lambda_{1} t_{m}}\right)\right] \\
& T_{\gamma}(\text { direct })_{M}=\varepsilon_{d} \varepsilon_{\gamma_{1}} \varepsilon_{t} N_{t} N_{b} \sigma_{1}\left(1-e^{-\lambda_{1} t_{b}}\right) \frac{1}{\lambda_{1}} e^{-\lambda_{1} t_{c}}\left(1-e^{-\lambda_{1} t_{m}}\right),
\end{aligned}
$$

where: $N_{t}$ is surface density of target atoms, [atom/ $\left./ \mathrm{cm}^{2}\right] ; N_{b}$ is number of bombarding particles per unit time, [proton/sec]; $\sigma_{i}$ is activation cross sections, $\left[\mathrm{cm}^{2}\right] ; f$ is decay branching ratio of ${ }^{99} \mathrm{Mo}$ to ${ }^{99 \mathrm{~m}} \mathrm{Tc} ; \varepsilon_{d}$ is detector efficiency; $\varepsilon_{\gamma}$ is corresponding gamma intensity; $\varepsilon_{t}$ is dead time correction; $\lambda_{i}$ is decay constant, [1/sec]; $t_{b}$ is bombarding time, [sec]; $t_{c}$ is cooling time, [sec]; $t_{m}$ is acquisition, [sec]; $i$ is the $i=1$ index refers to the ${ }^{99}$ Mo parent radionuclide, $i=2$ is referred to the ${ }^{99 \mathrm{~m}} \mathrm{Tc}$ daughter radionuclide instead.

Following the above data, the independent experiments were performed at 38,36 and $16 \mathrm{MeV}$ proton energies. The stacked foil technique, proton activation and high resolution gamma-spectrometry methods were used for measuring the cross sections of the ${ }^{100} \mathrm{Mo}(\mathrm{p}, 2 \mathrm{n})^{99 \mathrm{~m}} \mathrm{Tc}$ reaction using thin molybdenum foils in metallic form with natural isotopic composition as target. The 36 and $16 \mathrm{MeV}$ 
irradiations were new experiments, while the $38 \mathrm{MeV}$ irradiation was done earlier with results published in 2003. This experiment was re-evaluated by using up-to-date decay data and upgraded recommended cross sections for the ${ }^{\text {nat }} \mathrm{Ti}(\mathrm{p}, \mathrm{x})^{48} \mathrm{~V}$ monitor reaction.

The excitation function of the ${ }^{100} \mathrm{Mo}(\mathrm{p}, 2 \mathrm{n}){ }^{99 \mathrm{~m}} \mathrm{Tc}$ reaction determined in the three independent irradiations using analytically derived equations and the data evaluation are in perfect agreement. This agreement proves that the main discrepancy among the published experimental cross section data of the ${ }^{100} \mathrm{Mo}(\mathrm{p}, 2 \mathrm{n}){ }^{99 \mathrm{~m}} \mathrm{Tc}$ reaction could originate from the data evaluation methods.

New experimental results were cross checked by evaluating additional non-interfering reactions ${ }^{\text {nat }} \mathrm{Mo}(\mathrm{p}, \mathrm{x})^{95 \mathrm{~m}} \mathrm{Tc}$ and ${ }^{\text {nat }} \mathrm{Mo}(\mathrm{p}, \mathrm{x})^{96 \mathrm{~g}} \mathrm{Tc}$ reactions which are in a good agreement with the earlier published data.

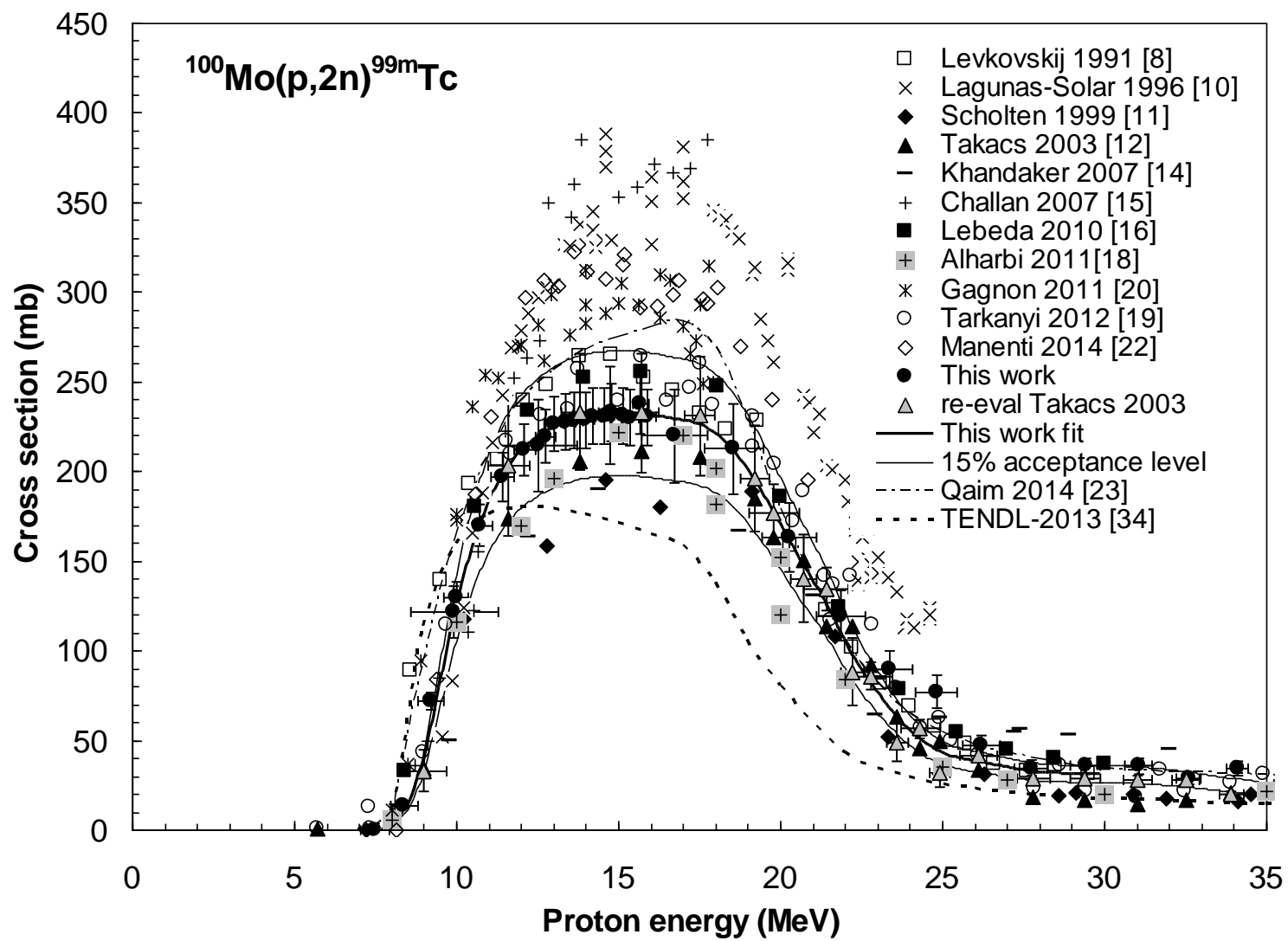

Figure 2. The newly-measured cross section data of the ${ }^{100} \mathrm{Mo}(\mathrm{p}, 2 \mathrm{n})^{99 \mathrm{~m}} \mathrm{Tc}$ reaction in comparison with the data reported earlier. The thick solid line is a spline fit of the results of this work and the re-evaluated data of published in 2003 . Thin lines indicate a $\pm 15 \%$ acceptance level.

Detailed information on the experiment and the derived results will be published in Nuclear Instruments and Methods B. 


\subsection{Definitions of yields. Problems and confusions, S. Takacs}

There is some confusion among the different definitions and use of the experimental yields of charged particle induced reactions in everyday use. Different physical quantities like production rates, EOB activity (activity at the end of bombardment) are called yield and the applied units are mixed up as well which makes proper compilation of the reported data difficult.

The yield of a nuclear reaction is defined as the ratio of the number of new nuclei formed in the nuclear reaction to the number of particles incident on the target. This yield is termed as the physical yield, $Y$ and the corresponding unit is particle/particle.

For charged particle induced reactions the number of incident particles can also be expressed by the corresponding charge of the number of bombarding particles. So, the unit of the yield can be particle/charge, particle/C, particle/ $\mu \mathrm{Ah}$ etc. (where the $\mu \mathrm{Ah}$ represents charge unit and not $\mu \mathrm{A} * \mathrm{~h}$ ).

The yield is always:

- target specific

- depends on the energy of the bombarding particles

- a time independent quantity.

There are fewer problems in the compilation of yields of stable reaction products which are always expressed in terms of the number of product particles per number of beam particles or in units of electric charge in case of charged particle beam. Since the reaction products are stable, the yield is "time independent".

Although the yield of a reaction with radioactive products can be expressed in the same manner, in the every-day practice some other physical quantities such as production rate or activity are used as yield, and this is a major source of confusion. Description on definitions of the used "experimental yield" is often insufficient or even missing in the literature. For radioactive reaction products it is widely accepted that the number of produced particles is determined by the measured activity. The unit of yield then is expressed as Activity/Charge $(\mathrm{MBq} / \mathrm{C}, \mathrm{MBq} / \mu \mathrm{Ah},(\mu \mathrm{Ah}$ is a charge unit). In an experiment not the yield but the number of decays is measured directly. The main problem arises from the fact that the activity is not time independent, and several time-dependent corrections should be applied to the measured activity in order to determine the proper number of the produced particles.

Experimental data of more than 800 works, which present experimental excitation functions and thick target yields were determined by measurements of activities followed by charged-particle irradiation, are already included in the EXFOR library.

In order to retrieve and analyse experimental thick target yields of a specific type from EXFOR efficiently and properly, each experimental data set must be properly tagged not only by the reaction type (i.e., target, beam particle, radioisotope product), but also by the definition of the yield. However, the large variety of yield nomenclature that can be found in the literature makes compilation work difficult.

\section{Thin- and Thick-Target Yield}

Thick-target Yield is defined as the yield of a reaction measured on a target with such a thickness in which the energy of the incident beam degrades to below the threshold energy of the reaction.

Thin-target yield is defined as the yield of a reaction measured on a target with such a thickness in which the energy of the incident beam degrades less significantly and the energy of the particles passing through the target is above the threshold energy of the reaction. 


\section{Production and decay rates}

For any target thickness the number of reaction product formed during irradiation can be described as follows. If the cross section to produce the isotope $i$ is $\sigma_{\mathrm{i}}(\mathrm{x})$, the total number of the produced isotope $i$ after irradiation time $t$ is $N(t)$ (not considering any decay, just production).

$$
\begin{aligned}
& \approx t I_{0} \int_{E_{L}}^{E_{0}} d E\left(-\frac{d E}{\rho d x}\right)^{-1} \sigma_{i}(E)(S / Z e) \\
& N(t)=t I_{0} y,
\end{aligned}
$$

where $E_{L}$ is the beam energy at the exit of the sample, $-(1 / \rho)(d E / d x)$ is the stopping power, and $y$ is the number of the isotope $i$ produced by deposition of unit charge (e.g., $1 \mathrm{C}$ ). The quantity $\boldsymbol{y}$ (in nuclides/C) describes the amount of produced particles in the target per unit charge; therefore it is called production rate. This quantity can be defined for both stable and radioactive products and it is time independent.

If the isotope $i$ is radioactive (with decay constant $\lambda$ ), the total number $N^{*}(t)$ of the radioisotope $i$ present in the target after irradiation time $t$ satisfies the following differential equation

$$
\frac{d N^{*}(t)}{d t}=I_{0} y-\lambda N^{*}(t)
$$

and its solution is

$$
N^{*}(t)=I_{0} y \frac{1-e^{-\lambda t}}{\lambda} .
$$

Experimentally, the activity of the produced nuclides is measured and the production rate can be deduced from the measured activity $A(t)$

$$
A(t)=\lambda N^{*}(t)=I_{0} y\left(1-e^{-\lambda t}\right) \equiv I_{0} a(t),
$$

where $a(t)$ defined as the decay rate or specific activity per unit current $(B q / \mu A)$ at the irradiation time $t$. The decay rate is a time dependent quantity.

The limit of equation (5) at $t \rightarrow \infty$ and its derivate at $t=0$ have special importance.

For a very long irradiation time (i.e., $t$ much longer than the half-lives of the reaction product) the value of the $\left(1-e^{-\lambda t}\right) \approx 1$, and the production rate and decay rate of the reaction product are in equilibrium.

$$
A(t \rightarrow \infty)=I_{0} y \equiv I_{0} a_{\text {sat }},
$$

where $a_{\text {sat }}$ defined as the saturation decay rate or saturation specific activity per unit current $(B q / \mu A)$ after a very long irradiation time.

The curve of the growing activity of the produced radionuclide versus irradiation time described by equation (5) is not a straight line. From Eq. (5), the time evolution of the activity during irradiation is described as:

$$
\begin{aligned}
& \frac{d A(t)}{d t}=I_{0} \lambda y e^{-\lambda t} \equiv I_{0} \alpha(t) \\
& \alpha(t=0)=\lambda y .
\end{aligned}
$$

Equation (8) describes the slope of the growing activity curve versus time. The value of $\alpha(t)$ at $t=0$ has a special importance, it is the production rate $(y)$ times decay constant $(\lambda)$ which gives the decay rate at $t=0$. This time-independent quantity with units of $\mathrm{Bq} / \mathrm{C}$ is defined as the physical yield. 


\begin{tabular}{|c|c|c|c|}
\hline Quantities defined in EXFOR & Symbol & & Typical unit \\
\hline hick target product yield & $\mathrm{y}$ & ,PY,TT/CH & $\begin{array}{l}\text { nuclei } / \mu \mathrm{C}, \\
\text { nuclei } / \mu \mathrm{Ah}\end{array}$ \\
\hline end-of-bombardment thick target yield & $a(t)$ & ,TTY„ЕOB & $\mathrm{MBq} / \mu \mathrm{A}$ \\
\hline saturation thick target yield & $\begin{array}{c}a_{\text {sat }} \\
a(t \rightarrow \infty)\end{array}$ & ,TTY,SAT & $\mathrm{MBq} / \mu \mathrm{A}$ \\
\hline physical thick target yield & $\begin{array}{c}\alpha_{\text {phys }} \\
\mathrm{a}(\mathrm{t}=0)\end{array}$ & ,TTY,PHY & $\mathrm{MBq} / \mathrm{C}$ \\
\hline
\end{tabular}

\subsection{Neutron Kerma factors in EXFOR: actual status and missing published results, S. Simakov}

KERMA $(K)$ is a Kinetic Energy Released in Matter per mass unit, $K=d E / d m . K$ accounts for the energy deposition from all charged ejectiles $(p, d, \alpha, e)$ of nuclear reaction including heavy recoils which deposit their energy locally. However, it excludes neutral reaction products $(n, \gamma, \ldots)$ which deposit energy non-locally, i.e. at "large" distance from collision.

The KERMA factor $k_{f}$ is defined as KERMA per incident particle fluence $\Phi=N /$ Area:

$$
\mathrm{k}_{\mathrm{f}}=\mathrm{K} / \Phi .
$$

$k_{f}$ is a product of mean ejectile energy $E_{j}$ and production cross section $\sigma_{j}$ summed over all reaction channels $j$ and is normalized per target atom mass $M$ :

$$
\mathrm{k}_{\mathrm{f}}(\mathrm{E})=\sum_{\mathrm{j}} \mathrm{k}_{\mathrm{j}}=\frac{\sum_{\mathrm{j}} \mathrm{E}_{\mathrm{j}} \sigma(\mathrm{n}, \mathrm{xj})}{\mathrm{M}} .
$$

Units of KERMA factors are Energy/Mass*Area and expressed either in $J / k g m^{2}$ and $G y m^{2}$ (SI) or in $\mathrm{erg} / \mathrm{g} \mathrm{cm}^{2}$ and $\mathrm{rad} \mathrm{cm}^{2}$ (CGS).

KERMA factors are used:

- In Reactor and Radiation Material Physics: Kerma factors after partitioning between electron ionization losses and atom recoils energies gives the Damage Energy that defines the number of Primary Kick-off Atoms (PKA) shifted from the lattice sites and finally the displacement-peratom probability or dpa-cross-sections. This is, in particular, a point of interest for the IAEA CRP on "Primary Radiation Damage Cross Sections": https://www-nds.iaea.org/CRPdpa/;

- In Medicine: Neutron Kerma factors are used to predict the ionization coursed by the secondary charged particles from neutron reactions in the human tissue or in Tissue Equivalent Plastics (TEP) such as A-150;

- More generally, for the Validation of Evaluated cross section Libraries: KERMA provides additional data for confidence.

EXFOR Documents have at the moment the following information about KERMA factors:

- LEXFOR (IAEA-NDS-208, rev 2011/01) has no information about KERMA at all;

- EXFOR Basics (IAEA-NDS-206, June 2008) defines in Dictionary 236 the specific Kerma factor parameter in subfield SF6 as ,KER ;

- EXFOR Protocol (IAEA-NDS-0215, rev 2014/05) categories a compilation scope for Kerma as "voluntary compilation (B)" and "Kerma factors (integral data only)". 
Currently EXFOR contains the measured $K_{f}$ data published by following authors:

- U. Schrewe et al., Entry 22507: results from paper presented at ND-1997 Trieste for 8 elements and 3 materials (however the author' data were wrongly converted into $\mathrm{fGy}^{*} \mathrm{~m}^{2}$ units and likely these data have to be superseded by those published in Phys. Med. Biol. 45, 651 (2000));

- S. Benck et al., Entry 22811: (Al) and 22807.45 (Si);

- E. Raeymackers et al., Entry 22942: Bi and U, total and partial $K_{f}$;

- M.A. Lone et al. Entry D0592.003: Kerma-rates in Air at $125 \mathrm{~cm}$ from Be(d,xn) source.

After an overview of Kerma data available in EXFOR and published in the literature (Table), the following proposals have been made:

- compile articles with neutron KERMA factors listed in Table;

- revisit and eventually correct Entry $\underline{22507}$ (include data from the later publication, correct units) and Entry 22811 (correct main reference).

Table. The KERMA data published in literature but missing in EXFOR

\begin{tabular}{|c|c|c|c|c|}
\hline $\begin{array}{c}\text { Target } \\
\text { Reaction }\end{array}$ & Energy & $\begin{array}{l}\text { Source } \\
\text { Lab }\end{array}$ & Reference & $\begin{array}{c}\text { Recommen } \\
\text { dation }\end{array}$ \\
\hline $\mathrm{C}, \mathrm{Mg}, \mathrm{Fe}$ & $14.7 \mathrm{MeV}$ & $\begin{array}{l}\text { D-T } \\
\text { Univ. of } \\
\text { Kansas }\end{array}$ & $\begin{array}{l}\text { C. Wuu and L. Milavickas, "Determination of the Kerma } \\
\text { Factors in Tissue-equivalent Plastic. C, Mg, and Fe for } \\
14.7 \mathrm{MeV} \text { Neutrons," } \\
\text { Med. Phys. 14(6), 1007 (1987) }\end{array}$ & $\begin{array}{l}\text { compile in } \\
\text { EXFOR }\end{array}$ \\
\hline $\mathrm{C}, \mathrm{Mg}, \mathrm{Fe}$ & $15.0 \mathrm{MeV}$ & $\begin{array}{c}\text { D-T } \\
\text { LLNL }\end{array}$ & $\begin{array}{l}\text { E. Goldberg, D.R. Slaughter and R.H. Howell, } \\
\text { "Experimental Determination of Kerma Factors at E } \approx 15 \\
\text { MeV", } \\
\text { LLL Report UCID-17789, } 1978\end{array}$ & $\begin{array}{l}\text { compile in } \\
\text { EXFOR }\end{array}$ \\
\hline $\mathrm{C}$ & $\begin{array}{l}14.1 \mathrm{MeV} \\
15,17.8 \\
\mathrm{MeV} \\
19.8 \mathrm{MeV}\end{array}$ & $\begin{array}{l}\text { RTNS-I } \\
\text { LLNL }\end{array}$ & $\begin{array}{l}\text { P.M. DeLuca, Jr., H.H. Barschall, R.C. Haight, and J.C. } \\
\text { McDonald, "Kerma factor of carbon for } 14.1 \mathrm{MeV} \\
\text { neutrons', } \\
\text { Radiation Research 100, 78-86 (1984) } \\
\text { P.M. DeLuca, Jr., H.H. Barschall, R.C. Haight, and J.C. } \\
\text { McDonald, "Measured neutron carbon kerma factors from } \\
14.1 \mathrm{MeV} \text { to } 18 \mathrm{MeV,"'} \mathrm{Proc.} \mathrm{of} \mathrm{5th} \mathrm{Symp.} \mathrm{Neutron} \\
\text { Dosim., v I: Luxembourg, 1985, No. EUR 9762 EN, pp. } \\
\text { 193-200. } \\
\text { P.M. DeLuca, Jr., H.H. Barschall, M. Burhoe, and R.C. } \\
\text { Haight, "Carbon kerma factor for 18- and 20-MeV } \\
\text { neutrons,", } \\
\text { Nucl. Sci. Eng. } 94 \text { (1986) 192-198 }\end{array}$ & $\begin{array}{l}\text { compile in } \\
\text { EXFOR }\end{array}$ \\
\hline $\mathrm{O}, \mathrm{Al}, \mathrm{Si}$ & $\begin{array}{c}15,17.5 \\
18.1,19.1 \\
\mathrm{MeV}\end{array}$ & $\begin{array}{l}\text { RTNS-I } \\
\text { LLNL }\end{array}$ & $\begin{array}{l}\text { P.M. DeLuca, H.H. Barschall, H.H. Sun, } \\
\text { R.C. Haight, 'Kerma factor of Oxygen, Aluminium and } \\
\text { Silicon for } 15 \text { and } 20 \mathrm{MeV} \text { neutrons } \\
\text { Radiat. Protect. Dosimetry } 23 \text { (1988) } 27\end{array}$ & $\begin{array}{l}\text { compile in } \\
\text { EXFOR }\end{array}$ \\
\hline $\mathrm{C}$ & $14.1 \mathrm{MeV}$ & $\begin{array}{c}\text { D-T } \\
\text { LLNL } \\
\end{array}$ & $\begin{array}{l}\text { R.C. Haight, S.M. Grimes et al. } \\
\text { NSE } 87 \text { (1984) } 41\end{array}$ & $\begin{array}{l}\text { compile in } \\
\text { EXFOR }\end{array}$ \\
\hline $\begin{array}{l}\mathrm{H} \\
\mathrm{C}, \mathrm{N}, \mathrm{O}\end{array}$ & $\begin{array}{l}25.8,50.0, \\
63.1 \mathrm{MeV} \\
27.4,39.7 \\
60.7 \mathrm{MeV}\end{array}$ & $\begin{array}{l}{ }^{7} \mathrm{Li}(\mathrm{p}, \mathrm{n}) \\
\text { Crocker } \\
\text { Nucl. Lab. } \\
\text { Uni. of } \\
\text { CA }\end{array}$ & $\begin{array}{l}\text { J.L. Romero, F.P. Brady, and T.S. Subramanian, “Neutron } \\
\text { induced charged particle spectra and kerma from } 25 \text { to } 60 \\
\text { MeV,”, } \\
\text { Santa Fe - 1985, v. 1, pp. 687-699 }\end{array}$ & $\begin{array}{l}\text { compile in } \\
\text { EXFOR }\end{array}$ \\
\hline
\end{tabular}




\begin{tabular}{|c|c|c|c|c|}
\hline $\begin{array}{c}\text { Target } \\
\text { Reaction } \\
\end{array}$ & Energy & $\begin{array}{c}\text { Source } \\
\text { Lab } \\
\end{array}$ & Reference & $\begin{array}{c}\text { Recommen } \\
\text { dation }\end{array}$ \\
\hline $\mathrm{C}, \mathrm{Mg}, \mathrm{Fe}$ & $\begin{array}{l}18,23,25 \\
\text { MeV } \\
\text { (Data on } \\
\text { Graph) }\end{array}$ & $\begin{array}{c}\mathrm{T}(\mathrm{d}, \mathrm{n}) \\
\text { Uni. of } \\
\text { Wisconsin }\end{array}$ & $\begin{array}{l}\text { C.L. Hartmann, P.M. DeLuca, Jr., and D.W. Pearson, } \\
\text { 'Measurement of neutron kerma factors in C, O, and Si at } \\
\text { 18, 23, and } 25 \text { MeV,' } \\
\text { Radiat. Protect. Dosim. 44, } 25 \text { (1992) } \\
\text { C.L. Hartmann, P.M. DeLuca Jr., D.W. Pearson, } \\
\text { 'Measurement of C, Mg and Fe Kerma Factors and the } \\
{ }^{19} F(n, 2 n){ }^{18} \text { F Cross Section for } 18 \text { to } 27 \text { MeV Neutrons' } \\
\text { ND-1991, Jülich, pp. 589-591 } \\
\text { C.L. Hartmann, "Measurements of Neutron Kerma Factors } \\
\text { at } 18,23 \text { and } 25 \text { MeV", } \\
\text { Ph.D. Thesis, University of Wisconsin, Madison, } 1991\end{array}$ & $\begin{array}{l}\text { compile in } \\
\text { EXFOR }\end{array}$ \\
\hline $\mathrm{Mg}, \mathrm{Si}, \mathrm{Fe}$ & $\begin{array}{l}25 \text { to } 85 \\
\mathrm{MeV} \\
34 \text { to } 66 \\
\mathrm{MeV}\end{array}$ & $\begin{array}{l}\text { WNR by } \\
\text { ToF } \\
\text { LANL } \\
\text { and } \\
\text { PSI }\end{array}$ & $\begin{array}{l}\text { W.D. Newhauser, "Neutron Kerma Factor Measurements } \\
\text { in the } 25 \mathrm{MeV} \text { to } 85 \mathrm{MeV} \text { Neutron Energy Range", } \\
\text { Ph.D. Thesis, University of Wisconsin, Madison, } 1995 \\
\text { here } \\
\text { Abstract: Medical Physics 22(1995)2128 }\end{array}$ & $\begin{array}{l}\text { compile in } \\
\text { EXFOR }\end{array}$ \\
\hline $\mathrm{C}$ & $\begin{array}{c}26.5-72.8 \\
\mathrm{MeV}\end{array}$ & $\begin{array}{l}\text { Cyclotron } \\
\text { Li(p,n) } \\
\text { Louvain- } \\
\text { la-Neuve }\end{array}$ & $\begin{array}{l}\text { I. Slypen, V. Corcalciuc and J.P. Meulders, 'Kerma values } \\
\text { deduced from neutron-induced charged-particle spectra of } \\
\text { carbon from 40-MeV to 75-MeV' } \\
\text { Phys. in Med. and Biol. 40, 73-82 (1995) } \\
\text { I. Slypen, S. Benck, J.P. Meulders, V. Corcalciuc, } \\
\text { 'Experimental partial and total kerma coefficients for } \\
\text { carbon deduced from microscopic cross sections at incident } \\
\text { neutron energies below } 75 \mathrm{MeV} \text { " } \\
\text { Phys. in Med. and Biol. } \mathbf{4 5} \text { (2000) } \mathbf{5 7 7}\end{array}$ & $\begin{array}{l}\text { compile in } \\
\text { EXFOR }\end{array}$ \\
\hline $\begin{array}{l}\mathrm{H}, \mathrm{C}, \mathrm{O}, \mathrm{N} \\
\text { A-150, TE- } \\
\text { M, TE-P, } \\
\mathrm{H}_{2} \mathrm{O}, \text { ICRU } \\
\text { muscle, } \\
\mathrm{H}\end{array}$ & $\begin{array}{c}29.0 \text { to } 72.8 \\
\mathrm{MeV}\end{array}$ & $\begin{array}{l}\text { Cyclotron } \\
\text { Li(p,n) } \\
\text { Louvain- } \\
\text { la-Neuve }\end{array}$ & $\begin{array}{l}\text { J.P. Meulders, S. Benck, I. Slypen, V. Corcalciuc, } \\
\text { 'Experimental kerma coefficients of biologically important } \\
\text { materials at neutron energies below } 75 \mathrm{MeV} \text { ', } \\
\text { Medical Physics 27, 2541 (2000) } \\
\text { V. Corcalciuc, S. Benck, R. Malu, J.P. Meulders, I. Slypen, } \\
\text { "Experimental hydrogen kerma factors for incident neutron } \\
\text { energies from } 25 \text { to } 75 \mathrm{MeV} \text {, } \\
\text { Phys. in Med. and Biology 44(1999)719 }\end{array}$ & $\begin{array}{l}\text { compile in } \\
\text { EXFOR }\end{array}$ \\
\hline${ }^{12} \mathrm{C}\left(\mathrm{n}, \mathrm{n}{ }^{\prime} 3 \alpha\right)$ & $\begin{array}{c}11-35 \\
\mathrm{MeV}\end{array}$ & $\begin{array}{l}{ }^{9} \mathrm{Be}(\mathrm{d}, \mathrm{n}) \\
\text { Louvain- } \\
\text { la-Neuve }\end{array}$ & $\begin{array}{l}\text { B. Antolkovic, L. Slaus and D. Plenkovic, "Experimental } \\
\text { Determination of the Kerma Factors for the Reaction } \\
{ }^{12} \mathrm{C}\left(\mathrm{n}, \mathrm{n}^{\prime} 3 \mathrm{a}\right) \text { at } \mathrm{E}_{\mathrm{n}}=10-35 \mathrm{MeV"} \\
\text { Radiation Research 97(1984)253 }\end{array}$ & $\begin{array}{l}\text { compile in } \\
\text { EXFOR }\end{array}$ \\
\hline${ }^{12} \mathrm{C}(\mathrm{n}, \mathrm{n}, 3 \alpha)$ & $\begin{array}{c}11.9-19.0 \\
\mathrm{MeV}\end{array}$ & $\begin{array}{c}\mathrm{D}(\mathrm{d}, \mathrm{n}) \\
\mathrm{T}(\mathrm{d}, \mathrm{n}) \\
\text { PTB }\end{array}$ & $\begin{array}{l}\text { B. Antolkovic, G. Dietzes and H.Klein, "Secondary } \\
\text { Alpha Particle Spectra and partial Kerma Factors } \\
\text { of the reaction } n+{ }^{12} \mathrm{C}->n+3 \alpha \text { ", } \\
\text { Radiation Protect. Dosimetry 44(1992)31 }\end{array}$ & $\begin{array}{l}\text { compile in } \\
\text { EXFOR }\end{array}$ \\
\hline $\begin{array}{l}\mathrm{C}, \mathrm{N}, \mathrm{O} \\
\mathrm{Mg}, \mathrm{Al}, \mathrm{Si} \\
\mathrm{Fe}, \mathrm{Zr}, \mathrm{AlN} \\
\mathrm{Al}_{2} \mathrm{O} 3, \mathrm{Si}_{2} \\
\mathrm{~A}-150\end{array}$ & $\begin{array}{c}5,8,15,17 \\
34,44,66 \\
\mathrm{MeV}\end{array}$ & $\begin{array}{c}\mathrm{D}(\mathrm{d}, \mathrm{n}) \\
\mathrm{T}(\mathrm{d}, \mathrm{n}) \\
5-17 \mathrm{MeV} \\
\mathrm{PTB} \\
\\
{ }^{9} \mathrm{Be}(\mathrm{p}, \mathrm{xn}) \\
34-66 \mathrm{MeV} \\
\text { PSI } \\
{ }^{9} \mathrm{Be}(\mathrm{p}, \mathrm{xn}) \\
\text { PSI, } \\
\text { Switzerlan } \\
\text { d }\end{array}$ & 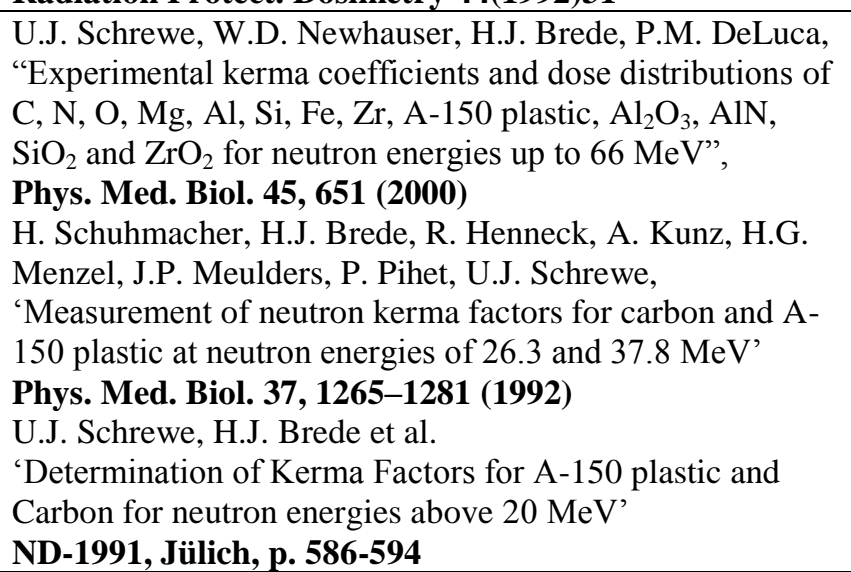 & $\begin{array}{l}\text { compile in } \\
\text { EXFOR }\end{array}$ \\
\hline
\end{tabular}




\begin{tabular}{|c|c|c|c|c|}
\hline $\begin{array}{c}\text { Target } \\
\text { Reaction }\end{array}$ & Energy & $\begin{array}{c}\text { Source } \\
\text { Lab }\end{array}$ & Reference & $\begin{array}{c}\text { Recommen } \\
\text { dation }\end{array}$ \\
\hline $\mathrm{Mg}$ & $\begin{array}{c}13.9,15.0 \\
19.0 \mathrm{MeV} \\
\\
13.9,15,17, \\
19 \mathrm{MeV} \\
15,17 \mathrm{MeV}\end{array}$ & $\begin{array}{l}\text { T(d,n) } \\
\text { PTB }\end{array}$ & $\begin{array}{l}\text { G. Buhler, H.G. Menzel, H. Schuhmacher, 'Neutron kerma } \\
\text { factors for magnesium and aluminium measured with low- } \\
\text { pressure proportional counters' } \\
\text { Phys. Med. Biol. } 31 \text { (1986) 601 } \\
\text { G. Buhler, H.G. Mentzel, H. Schuhmacher, S. Guldbakke, } \\
\text { 5th Symp. Neutr. Dos., Munich, EUR-9762, p. } 309 \\
\text { (1985) }\end{array}$ & $\begin{array}{l}\text { compile in } \\
\text { EXFOR }\end{array}$ \\
\hline $\mathrm{C}, \mathrm{A}-150$ & $\begin{array}{c}13.9-20 \\
\mathrm{MeV}\end{array}$ & $\begin{array}{l}\mathrm{T}(\mathrm{d}, \mathrm{n}) \\
\mathrm{PTB}\end{array}$ & $\begin{array}{l}\text { P. Pihet, S. Guldbakke, H.G. Menzel and H. Schuhmacher, } \\
\text { 'Measurement of kerma factors for carbon and A-150 } \\
\text { plastic: neutron energies from } 13.9 \text { to } 20.0 \mathrm{MeV} \text { ' } \\
\text { Phys. Med. Biol. 37, 1957 (1992) }\end{array}$ & $\begin{array}{l}\text { compile in } \\
\text { EXFOR }\end{array}$ \\
\hline $\mathrm{N}, \mathrm{O}, \mathrm{Ca}$ & $18-26 \mathrm{MeV}$ & $\begin{array}{l}\text { ?? } \\
\text { Ohio } \\
\text { Univ. }\end{array}$ & $\begin{array}{l}\text { M.S. Islam, R.W. Finlay, J.S. Petler, J. Rapaport, R. } \\
\text { Alarcon and J. Wierzbicki, 'Neutron scattering cross } \\
\text { sections and partial kerma values for oxygen, nitrogen and } \\
\text { calcium at } 18<\mathrm{E}_{\mathrm{n}}<60 \mathrm{MeV} \text { ' } \\
\text { Phys. Med. Biol. 33, } \mathbf{3 1 5}(\mathbf{1 9 8 8})\end{array}$ & $\begin{array}{l}\text { compile in } \\
\text { EXFOR }\end{array}$ \\
\hline $\mathrm{C}$ & $14.6 \mathrm{MeV}$ & $\begin{array}{l}\text { T(d,n) } \\
\text { RTNS-II, } \\
\text { LLNL }\end{array}$ & $\begin{array}{l}\text { J.C. McDonald, "Calorimetric measurements for the } \\
\text { carbon kerma factor for } 14.6-\mathrm{MeV} \text { neutrons," } \\
\text { Radiation Research } 109 \text { (1987) 28-35 }\end{array}$ & $\begin{array}{l}\text { compile in } \\
\text { EXFOR }\end{array}$ \\
\hline $\begin{array}{l}\text { C } \\
\text { total and } \\
\text { partial }\end{array}$ & $96 \mathrm{MeV}$ & $\begin{array}{l}{ }^{7} \operatorname{Li}(\mathrm{p}, \mathrm{n}) \\
\text { TSL } \\
\text { Uppsala. }\end{array}$ & $\begin{array}{l}\text { B.E. Bergenwall, A. Atac and S. Kullander, 'Experimental } \\
\text { kerma coefficients for carbon deduced from microscopic } \\
\text { cross sections at } 96 \mathrm{MeV} \text { incident neutron energy", } \\
\text { Phys. Med. Biol. 49, 4523 (2004) } \\
\text { P. Mermod, J. Blomgren, C. Johansson, A. Ohrn, M. } \\
\text { Osterlund, S. Pomp et al. "95 MeV neutron scattering } \\
\text { on hydrogen, deuterium, carbon, and oxygen", } \\
\text { Phys. Rev. C 74, 054002 (2006) }\end{array}$ & $\begin{array}{l}\text { compile in } \\
\text { EXFOR } \\
\text { has to be } \\
\text { added to } \\
\underline{23030}\end{array}$ \\
\hline $\begin{array}{l}\text { C } \\
\text { elastic and } \\
\text { ineal } \mathrm{k}_{\mathrm{f}}\end{array}$ & $\begin{array}{c}\mathrm{E}=16.5- \\
22 \mathrm{MeV}\end{array}$ & $\begin{array}{l}\mathrm{T}(\mathrm{d}, \mathrm{n}) \\
\text { gas target } \\
\text { University } \\
\text { Uppsala. }\end{array}$ & $\begin{array}{l}\text { N. Olsson, B. Trostell, E. Ramstroem, "Cross sections and } \\
\text { partial KERMA factors for elastic and inelastic neutron } \\
\text { scattering from Carbon in the energy range } 16.5-22.0 \\
\text { MEV", } \\
\text { Int. Conf. Nucl. Data Sci. \& Techn., Mito, 1988, } 1045\end{array}$ & $\begin{array}{l}\text { has to be } \\
\text { added to } \\
\underline{22098}\end{array}$ \\
\hline$?$ & $? ?$ & $? ? ?$ & $\begin{array}{l}\text { L.S. August, P. Shapiro, R.B. Theus, Cross Sections and } \\
\text { Yields for High Energy Neutron Source Reactions. } \\
\text { National Bureau of Standards Report NBSIR 77-1279, } \\
\text { pp. 31-34, 1977 }\end{array}$ & $? ? ?$ \\
\hline
\end{tabular}

\subsection{Some problems of photonuclear data compilation and evaluation, V. Varlamov}

Experimental photonuclear data research is a complicated problem for several reasons:

- absence of intensive monoenergetic photon beams (experimentalists are forced to use special methods for production of quasimonoenergetic photon beams or to use special mathematical methods for unfolding the results obtained using electron bremsstrahlung);

- photoneutron reaction contribution as a main part of Giant Dipole Resonance (experimentalists are forced to detect neutrons using detectors with low efficiency and not sufficient accuracy for measurements of neutron energies);

- direct methods of neutron registration frequently lead to missing contributions of accompanying protons (because of low and close values of the correspondent reaction thresholds);

- activation methods have many restrictions due to the properties of final nucleus decay. 
As a result we have many data with significant systematic uncertainties obtained with the different experimental measurement methods and/or data processing procedures. Therefore, there are many problems in photonuclear data compilation and evaluation.

\section{Total reaction $\mathrm{SF1}(\mathrm{G}, \mathrm{SF3}) \mathrm{SF} 4, \mathrm{SIG})$ definition}

In many sources of information a definition $(\gamma, \mathrm{Sn})$ is used for neutron yield reaction $(\gamma, \mathrm{Sn})=(\gamma, 1 \mathrm{n})+$ $2(\gamma, 2 \mathrm{n})+3(\gamma, 3 \mathrm{n})-\mathrm{SF} 1(\mathrm{G}, \mathrm{X}) 0-\mathrm{NN}-1, \mathrm{SIG})$, but in many others - for total photoneutron reaction $(\gamma, \mathrm{Sn})$ $=(\gamma, 1 \mathrm{n})+(\gamma, 2 \mathrm{n})+(\gamma, 3 \mathrm{n})-\mathrm{SF} 1(\mathrm{G}, \mathrm{X}) 0-\mathrm{NN}-1, \mathbf{U N W}, \mathrm{SIG})$.

Therefore, the compiler should be very careful $(\gamma, \mathbf{S n})$.

\section{Partial reaction $\mathrm{SF} 1(\mathrm{G}, \mathrm{N}(2 \mathrm{~N})(3 \mathrm{~N})) \mathrm{SF} 4, \mathrm{SIG})$ definition}

In experiments with the direct identification of the reaction via final nucleus SF4 using the method of induced activity the final nuclei are different, having different spectra of de-excitation g-quanta and, therefore, SF4 defines SF3: $(\gamma, 1 \mathrm{n}),(\gamma, 2 \mathrm{n}),(\gamma, 3 \mathrm{n})$, etc.

In experiments using the direct neutron multiplicity sorting methods, $(\gamma, 1 \mathrm{n})$ and $(\gamma, 2 \mathrm{n})$ reactions are separated by detection of neutrons with different energy and therefore SF3 defines SF4. In such cases, reactions with different outgoing particles can occur at the same energies: not $(\gamma, 1 \mathrm{n})$ SF1 $(G, N) S F 4,, S I G)$ but $(\gamma, 1 \mathrm{n})+(\gamma, 1 \mathrm{np})-[\mathrm{SF} 1(\mathrm{G}, \mathrm{N}) \mathrm{SF} 4,, \mathrm{SIG})+\mathrm{SF} 1(\mathrm{G}, \mathrm{N}+\mathrm{P}) \mathrm{SF} 4 \mathrm{p},, \mathrm{SIG})]$ and possibly more $[(\gamma, 1 n)+(\gamma, 1 n 1 p)+(\gamma, 1 \ln 2 p)]$, etc.

Therefore, the compiler should be very careful in partial reaction definition.

\section{Systematic disagreements of data obtained with bremsstrahlung and quasimonoenergetic annihilation photons.}

\section{1 "Direct" measurement versus Inverse unfolding}

One can measure only the reaction yield Y - folding of a cross section investigated with continuous $\gamma$ spectrum using bremsstrahlung. The cross section is the result of solving the inverse unfolding task using one of the special mathematical methods (photon difference, inverse matrix, least structure, Penfold-Leiss, Tikhonov regularization, reduction, etc.) in accordance with the quasimonoenergetic presentation of effective $\gamma$-quanta spectrum with a definite energy resolution equal to the width of line in effective $\gamma$-spectrum.

An alternative to bremsstrahlung unfolding "direct" method of quasimonoenergetic annihilation photons is the three step difference procedure: i) measurement of reaction yield Yp with spectrum as the sum of photons from positron annihilation and bremsstrahlung, ii) measurement of yield Ye with photons from electron bremsstrahlung, iii) subtraction of second result from the first one and definition the result YpYe as cross section with resolution equal to annihilation line. However, this is impossible: difference between two results with bad resolution could not produce results with good resolution. If yes - that would be the "perpetuum mobile". As a result almost all cross sections obtained using annihilation photons look like smoothed version of those obtained using the bremsstrahlung unfolding.

The difference of two yields is yield $\mathrm{Yp}-\mathrm{Ye}=\mathrm{Y}$, not a cross section. Additional unfolding with simulated $\gamma$-spectrum leads to a cross section close to that obtained using bremsstrahlung unfolding. The real resolution of annihilation photons experiments is 4-6 time worse in comparison with annihilation line width.

Therefore, there are the problems for compilers and evaluators: if Yp-Ye is interpreted as cross section (INC-SOURE) (QMPH)) its resolution should be described as noticeably worse. If Ys-Ye = Y (not (QMPH) but not (BRST)) additional unfolding is needed. 


\subsection{Systematic disagreements of partial photoneutron reaction cross sections obtained using}

annihilation $n$ photons in different laboratories.

The majority of partial reaction cross sections was obtained using annihilation photons at the Livermore (USA) and Saclay (France) laboratories. Both laboratories employed the same assumption that the neutron spectra of $(\gamma, 1 \mathrm{n}),(\gamma, 2 \mathrm{n})$ and $(\gamma, 3 \mathrm{n})$ reactions, and the methods for neutron kinetic energy measurement used for multiplicity determination are quite different. Systematic discrepancies (up to $100 \%)$ in partial photoneutron reaction cross sections are well-known: in many cases for the same nuclei the $(\gamma, 1 \mathrm{n})$ reaction cross sections are noticeably larger at Saclay, but the $(\gamma, 2 \mathrm{n})$ cross sections vice versa at Livermore.

Some objective criteria for data reliability were found out for the transitional multiplicity functions the ratios of the definite partial reaction cross sections $\sigma(\gamma$, in $)$ to the neutron yield reaction cross section $\sigma(\gamma, \mathrm{Sn})=\sigma[(\gamma, 1 \mathrm{n})+2(\gamma, 2 \mathrm{n})+3(\gamma, 3 \mathrm{n})+\ldots]$. According to the definition $\mathrm{F}_{2}=\sigma(\gamma, 2 \mathrm{n}) / \sigma(\gamma, \mathrm{Sn})$ cannot exceed 0.50 in magnitude: larger value means a physically incorrect determination of $(\gamma, 2 \mathrm{n})$ and of $(\gamma, 1 \mathrm{n})$ reactions cross sections. The regions of physically unreliable values $\mathrm{F}_{2}>0.50$ (too large $\sigma(\gamma, 2 \mathrm{n})$ ) correlate with unreliable negative values (too small) in the $\sigma(\gamma, 1 \mathrm{n})$ reaction cross section. Correspondingly, $\mathrm{F}_{1}$ should $<1.00, \mathrm{~F}_{3}<0.33, \mathrm{~F}_{4}<0.25, \mathrm{~F}_{5}<0.20, \mathrm{~F}_{6}<0.17, \mathrm{~F}_{7}<0.14$, etc. If these functions (ratios) or Fi go beyond absolute limits mentioned that means that neutron multiplicity sorting was erroneous.

Investigations of ${ }^{90,91,94} \mathrm{Zr},{ }^{115} \mathrm{In},{ }^{112-124} \mathrm{Sn},{ }^{159} \mathrm{~Tb},{ }^{165} \mathrm{Ho},{ }^{181} \mathrm{Ta},{ }^{188,189,190,192} \mathrm{Os},{ }^{197} \mathrm{Au}$ and ${ }^{208} \mathrm{~Pb}$ experimental data obtained using neutron multiplicity sorting show that as a rule of thumb they do not satisfy proposed criteria of data reliability. A new method of evaluation based on the well-tested data combined with a theoretical model of photonuclear reactions was proposed as a method of satisfied introduced criteria. Initial data include experimental neutron yield reaction cross sections $\sigma^{\exp }(\gamma, \mathrm{Sn})$ and neutron multiplicity sorting functions calculated in the model $F_{i}$ theor: $\sigma^{\text {eval }}(\gamma$, in $)=F_{i}$ theor $\bullet \sigma^{\exp }(\gamma, S n)$. That means that the competition of partial reactions $(\gamma, 1 \mathrm{n}),(\gamma, 2 \mathrm{n}),(\gamma, 3 \mathrm{n}), \ldots$ is in accordance with equations of the model and the correspondent sum of evaluated partial reaction cross sections $\sigma^{\text {eval }}(\gamma, \mathrm{Sn})=\sigma^{\text {eval }}(\gamma, 1 \mathrm{n})+2 \sigma^{\text {eval }}(\gamma, 2 \mathrm{n})+3 \sigma^{\text {eval }}(\gamma, 3 \mathrm{n})-$ is equal to the experimental $\sigma^{\text {exp }}(\gamma, \mathrm{Sn})$.

Data evaluated using this approach noticeably disagree with both Saclay and Livermore data but agree with the data obtained using alternative activation method.

That means that many well-known experimental partial photoneutron reaction cross sections are not reliable and should be re-measured and/or evaluated using appropriate data reliability criteria.

\subsection{Compilation of neutron data in the resolved resonance region measured by TOF method. Spectrometers' response function, V. Semkova}

The nuclear data for the neutron-induced reaction in the resonance range have been extensively compiled in EXFOR. However, in many cases only the resonance parameters are reported. Some experimentalists have provided also raw data such as transmission and capture yields. The time-of-flight spectra are valuable for future analysis (reanalysis, simultaneous analysis) and compilation of them has been desired of the NRCD community for many decades. Proper analyses require additional experimental information such as sample thickness (affecting self- shielding, multiple collisions) and response function (RF). The spectrometers' response functions are needed for comparison of data measured at different experimental facilities. The resolution broadening has to be applied to evaluated data in order to compare experimental data with the evaluation. A template was developed at the Consultants' Meeting "EXFOR Data in Resonance Region and Spectrometer Response Function" that 
includes all essential information for a time-of-flight measurement. The template is available at the https://www-nds.iaea.org/index-meeting-crp/CM-RF-2013/ webpage and compilers are advised to use it in order to request and compile information from the experimentalists. In addition, the main uncertainty components have to be identified and the correlated and uncorrelated components have to be reported separately, preferably based on the AGS-concept.

During the Meeting, possibilities for the compilation in EXFOR of the TOF spectrometer response functions which is required for the neutron spectroscopy applications were discussed. The broadening components and the intrinsic widths of resonances are usually non-Gaussian and, therefore, need to be taken into account by a full convolution of the corresponding distributions. The RF consists of a number of independent contributions: the distribution of the pulsed charged particle beam, serving as a start of the time-of-flight measurement; the neutron producing target and moderator ensemble; interactions in the sample and detector ensemble; electronic noise from the signal processing and data acquisition system; the widths of the data binning. In the R-matrix codes (SAMMY, REFIT), the RFs are presented by analytical expressions that contain a number of components. The parameterization for the specific facility/experiment is usually obtained by a fitting procedure. Some experimentalists have recently submitted the analytical functions and the fitting parameters for their experiments to EXFOR. For some facilities the RFs have been determined by Monte Carlo simulations. While a parameterized analytical function may in some cases be an adequate description of a RF, nowadays Monte Carlo simulations can provide the RF in a detailed way. Storage of the RF in EXFOR in numerical form or possibly even as input file for a Monte Carlo description or R-matrix analysis codes would preserve this information in a sustainable way. The following recommendations for the development of the RF compilation rules in EXFOR were discussed during the Meeting:

- Best solution for target/moderator: matrix of (En, d) (use a dense enough grid for En and for d);

- Flexibility: allow also (En, t) or even (En, E') matrices (code input is often as (En, $t)$ );

- Flexibility: allow additional components in either time (pulse width), distance, or energy;

- For existing measurements, also supply support for analytical expressions;

- Possibility to associate several RFs with a measurement (for example, target/moderator + pulse width + sample/detector);

- Define unique and informative tags for RFs, allowing for possible upgrades of a particular RF.

\subsection{Neutron source spectra format. EXFOR formats and rules: present status and proposals for neutron source data storage, 0 . Gritzay}

The following proposal for the source spectral information storage in EXFOR was suggested in INDC(NDS)-0590 to introduce into EXFOR new special ENTRY/SUBENTRY for neutron spectrum.

New: type of spectrum and its characteristic should be entered in numeric data type using separate SUBENTRY or ENTRY for neutron spectrum if the spectrum is commonly applied to measurements performed at the neutron source.

1. Use special form of REACTION to define the neutron source (see table below) with the proper modifier SPD to REACTION SF8.

2. Use DATA to enter the numerical spectral data.

3. Data that are averaged over broad incident-projectile energy spectrum and entered into the EXFOR system, should be labelled by the keyword INC-SOURCE with use of all relevant keywords from the Inc-Source Dictionary (\#19) and the cross-reference to the EXFOR entry/subentry with these numerical spectral data.

4. This cross-reference must be coded as an eight-digit integer 
Unfortunately, this proposal was not realized.

We continue to use the following rules:

\section{LEXOR:}

Spectrum Average

Cross sections averaged over a broad incident-projectile energy spectrum may be entered into EXFOR using the proper modifier to REACTION SF8. The type of spectrum and its characteristic should be entered in free text under the information-identifier keyword INC-SPECT.

The following spectrum types are defined:

1. Maxwellian Average: Modifier MXW

2. The spectrum temperature should be given, if known. For thermal Maxwellian spectrum averaged data, see Thermal Neutron Energies.

3. Epithermal Spectrum Average: Modifier EPI

4. The energy quoted will be, typically the low energy cut off.

5. Fission-Neutron Spectrum Average: Modifier FIS

6. For details, see Fission-Neutron Spectra.

7. Fast Reactor Spectrum Average: Modifier FST

8. Bremsstrahlung Spectrum Average: Modifier BRA

9. The energy quoted will be, typically, EN-MAX, or EN-MIN with EN-MAX.

10. Average over "good resolution" Bremsstrahlung Spectrum: Modifier BRS

11. The energy quoted will be, typically, EN with EN-RSL.

12. Spectrum Average (unspecified Spectrum): Modifier SPA

13. Used for all other spectra, e.g., thermal reactor spectra. Care should be taken to compile only those data that would be of value to the user of EXFOR.

\section{EXFOR Formats Manual (Chapter 7):}

\section{INFORMATION-IDENTIFIER KEYWORDS AND CODING RULES}

INC-SPECT. Provides information on the characteristics and resolution of the incident-projectile beam. See also LEXFOR, Incident-Projectile Energy.

1. Must be present when a spectrum average modifier (e.g., MXW, SPA, or FIS) is present in REACTION SF8. See also LEXFOR, Spectrum Average. Otherwise its use is optional. No coded information.

However even if the data for the incident spectrum are provided in the compilation the spectrum retrieval is not easy and plotting is not possible with the current compilation rules.

Free text presentation of the incident spectrum makes the search difficult and plotting capabilities of the retrieval system cannot be applied. Such presentation is often lengthy. For example, in Subentry 22850001 it has 699 lines (from 769 lines); in Subentry 23075001 it has 230 lines (from 326 lines). The length of the text can be up to thousands of lines in case of spectra for average cross sections measured by proton recoil counters using the NFBT. If several spectra are compiled in free text it is very difficult to find where one ends and the next spectrum starts. is not convenient.

Based on the proposal given in the beginning the following revision of the LEXFOR manual is proposed: 


\section{Spectrum Average}

Cross sections averaged over a broad incident-projectile energy spectrum may be entered into EXFOR using the proper modifier to REACTION SF8. The type of spectrum and its characteristic should be entered in free text under the information-identifier keyword INC-SPECT or in numeric data type using separate special SUBENTRY or ENTRY.

Data that are averaged over broad incident-projectile energy spectrum and entered into the EXFOR system, should be labelled with the code DEP under the keyword STATUS, if the spectrum is entered into the EXFOR system in numeric data type.

In these special SUBENTRY/ ENTRY

1) use a special form of REACTION to define the neutron source (see table below) with the proper modifier SPD to REACTION SF8;

2) use DATA to enter the numerical spectral data.

\section{Dependent Data}

Data that are deduced by a trivial operation from other data sets entered into the EXFOR System or data, that are averaged over broad incident-projectile energy spectrum entered into the EXFOR system in numeric data type (using special SUBENTRY/ENTRY) should be labelled with the code DEP under the keyword STATUS. Free text under STATUS and/or ANALYSIS should give information as to how the data were deduced. Cross reference to the EXFOR entries from which the data were deduced or to the EXFOR entries with spectrum in numeric data type must be coded as an eight-digit integer following the code.

The EXFOR rules for INC-SPECT and INC-SOURCE remain the same.

The following coding is proposed in order to define the neutron source by REACTION:

REACTION is a reaction by which neutrons are generated.

$\mathrm{SF} 1$ - target, $\mathrm{SF} 2$ - incident particle (SF2=0 for spontaneous fission),

$\mathrm{SF} 3$ - outgoing particle/product $\mathrm{X}$ (SF3=F for spontaneous fission),

SF4 - outgoing neutron 0-NN-1,

SF6 - Differential with energy of outgoing particle (neutron),

SF8 - SF8=SPD - Spectrum Description, SPD/REL Relative data (ARB-UNITS)

SF9 - CALC/EXP Calculated/Experimental data

\begin{tabular}{|l|l|l|}
\hline Name of neutron source & In INC-SPECT & $\begin{array}{l}\text { SF1-SF8 in REACTION } \\
\text { in SubEntry with SF8= SPD }\end{array}$ \\
\hline Alpha-Beryllium & A-BE & 4-BE-9(A,X)0-NN-1,, DE,,SPD \\
\hline Americium-Beryllium ns & AM-BE & 4-BE-9(A,X)0-NN-1,, DE,,SPD ? \\
\hline Spont. fission of Californium-252 & CF252 & 98-CF-252(0,F)0-NN-1,, DE,,SPD \\
\hline Spont. fission of Curium-244 & CM244 & 96-CM-244(0,F) 0-NN-1,, DE,,SPD \\
\hline Spont. fission of Curium-246 & CM246 & 96-CM-246(0,F) 0-NN-1,, DE,,SPD \\
\hline Spont. fission of Curium-248 & CM248 & 96-CM-248(0,F) 0-NN-1,, DE,,SPD \\
\hline Deuteron-Beryllium & D-BE & 4-BE-9(D,X)0-NN-1,, DE,,SPD \\
\hline Deuteron-Carbon 12 & D-C12 & 6-C-12(D,X) 0-NN-1,, DE,,SPD \\
\hline Deuteron-Carbon 14 & D-C14 & 6-C-14(D,X) 0-NN-1,, DE,,SPD \\
\hline
\end{tabular}




\begin{tabular}{|c|c|c|}
\hline Name of neutron source & In INC-SPECT & $\begin{array}{l}\text { SF1-SF8 in REACTION } \\
\text { in SubEntry with SF8= SPD }\end{array}$ \\
\hline Deuteron-Deuterium & D-D & 1-H-2(D,X) 0-NN-1,, DE,,SPD \\
\hline Deuteron-Lithium & D-LI & 3-LI-0(D,X) 0-NN-1,, DE,,SPD \\
\hline Deuteron-Lithium 7 & D-LI7 & 3-LI-7(D,X) 0-NN-1,, DE,,SPD \\
\hline Deuteron-Nitrogen 14 & D-N14 & 7-N-14(D,X) 0-NN-1,, DE,,SPD \\
\hline Deuteron-Nitrogen 15 & D-N15 & 7-N-15(D,X) 0-NN-1,, DE,,SPD \\
\hline Deuteron-Tritium & D-T & 1-H-3(D,X) 0-NN-1,, DE,,SPD \\
\hline Evaporation neutrons & EVAP & $\begin{array}{l}\text { 13-Al-0(P,X) 0-NN-1,, DE,,SPD } \\
\text { 74-W-0(P,X) 0-NN-1,, DE,,SPD } \\
\text { 82-Pb-0(P,X) 0-NN-1,, DE,,SPD } \\
\text { 92-U-0(D,X) 0-NN-1,, DE,,SPD } \\
\ldots\end{array}$ \\
\hline Nuclear explosive device & EXPLO & $\begin{array}{l}\text { Entries with SPA are absent in EXFOR. } \\
\text { Time-of-flight method was used }\end{array}$ \\
\hline Proton-Beryllium & P-BE & 4-BE-9(P, X) 0-NN-1,, DE,,SPD \\
\hline Proton-Deuterium & P-D & 1-H-2(P, X) 0-NN-1,, DE,,SPD \\
\hline Photo-neutron & PHOTO & $\begin{array}{l}\text { 1-H-2(G,X) 0-NN-1,, DE,,SPD } \\
\text { 13-Al-0(G,X) 0-NN-1,, DE,,SPD } \\
\text { 92-U-0(G,X) 0-NN-1,, DE,,SPD } \\
\ldots\end{array}$ \\
\hline Proton-Lithium 7 & P-LI7 & 3-LI-7(P,X) 0-NN-1,, DE,,SPD \\
\hline Polarized neutron source & POLNS & Entries with SPA are absent in EXFOR. \\
\hline Proton-Tritium & P-T & 1-H-3(P,X) 0-NN-1,, DE,,SPD \\
\hline Plutonium-Beryllium ns & AM-BE & 4-BE-9(A,X) 0-NN-1,, DE,,SPD ? \\
\hline Spont. fission of Plutonium-240 & PU240 & 94-PU-240(0,F) 0-NN-1,, DE,,SPD \\
\hline Spont. fission of Plutonium-242 & PU242 & 94-PU-242(0,F) 0-NN-1,, DE,,SPD \\
\hline Reactor & REAC & $\begin{array}{l}\text { 92-U-235(N,X) 0-NN-1,, DE,,SPD } \\
\text { or 92-U-0(N,X) 0-NN-1, DE,,SPD }\end{array}$ \\
\hline Thermal column & THCOL & 92-U-235(N,X) 0-NN-1,, DE,,SPD \\
\hline Thorium-Beryllium ns & TH-BE & 4-BE-9(A,X) 0-NN-1,, DE,,SPD ? \\
\hline
\end{tabular}

An example of a compilation of an experiment with filtered neutron beam is given below:

\begin{tabular}{|c|c|}
\hline 20140507 & 322380 \\
\hline 20140507 & 32238 \\
\hline BIB & 32238 \\
\hline INSTITUTE (4UKRIJD, 4UKRUKR) 4UKRUKR - State Scientific-Engineering & 322381 \\
\hline Center for Control and Emergency Response, Kyiv & 322381 \\
\hline REFERENCE (C,2012KYIV, 430,2013$)$ & 3223815 \\
\hline AUTHOR (O.O.Gritzay, A.K.Grymalo, V.V.Kolotyi, V.A.Pshenychnyi, V.P.Shakhov, V.M. & nedykt \\
\hline $\begin{array}{l}\text { TITLE Determination of total neutron cross section of } 52 \mathrm{Cr} \text { with using average ene } \\
\text { shift method for filtered neutron beam }\end{array}$ & \\
\hline FACILITY (REAC, 4UKRIJD) Reactor WWR-M & 32238 \\
\hline INC-SOURCE (REAC) Neutron filter installed in horizontal channel of the reactor. & 32238 \\
\hline Filter components: S-116.53 g/cm2, & 32238 \\
\hline $58 \mathrm{Ni}-81.42 \mathrm{~g} / \mathrm{cm} 2, \mathrm{~V}-24.44 \mathrm{~g} / \mathrm{cm} 2, \mathrm{Al}-5.4 \mathrm{~g} / \mathrm{cm} 2,10 \mathrm{~B}-0.5 \mathrm{~g} / \mathrm{cm} 2$ & 32238 \\
\hline The calculated energy and width of the neutron line (95\% response function) after & 32238116 \\
\hline this filter are: $59(+1.2,-6.7) \mathrm{keV}$ & 32238117 \\
\hline Calculated and experimental spectra after this filter are presented & 32238 \\
\hline in 32238002 and 32238003 & 120 \\
\hline INC-SPECT The initial neutron line with the average energy $59 \mathrm{keV}$ produces at the & 121 \\
\hline 15, 20 and 25 ADEG the scattered neutron lines with the av & \\
\hline
\end{tabular}


energies 55, 52, $48.4 \mathrm{keV}$ and $58.6,58.3,58 \mathrm{keV}$ if neutrons are scattered by

$\begin{array}{lll}32238 & 1 & 23\end{array}$

hydrogen and carbon, respectively. Thickness of the used scattering-samples $C$ and $\mathrm{CH} 2$ was $10.02+-0.01$ and $4.52+-0.01 \mathrm{~mm}$.

METHOD (FNB, TRN) Transmission measurement of the scattered filtered neutrons.

32238125

32238126

32238128

32238130

diameter-38.1 mm length-254.0 mm, gas pressure-3240 torr)

SAMPLE 52Cr sample was made of a metal powder, loaded into aluminum container.

$32238 \quad 131$

$32238 \quad 133$

$32238 \quad 134$

32238136

STATUS (TABLE) From text

HISTORY (20140425) UKRNDC

ENDBIB

350

NOCOMMON

ENDSUBENT

$\begin{array}{ll}0 & 0 \\ 38 & 0\end{array}$

SUBENT

32238002

0

$32238 \quad 137$

32238138

32238139

32238199999

$32238 \quad 2 \quad 1$

$32238 \quad 2 \quad 2$

3223823

REACTION (92-U-235 (N, X) 0-NN-1, DE, SPA/REL, CALC)

Calculated was done by FILTER-7 using JENDL-3.3 (58Ni-81.42 g/cm2, $10 \mathrm{~B}-0.5 \mathrm{~g} / \mathrm{cm} 2$, 11B-0.088 g/cm2, 27Al-5.4 g/cm2, Vnat-24.44 g/cm2), CENDL-2 (Snat-116.53 g/cm2).

Calculated energy line is $58.98 \mathrm{keV}$, purity about 95\%. The limits of 95\% response function for the $59 \mathrm{keV}$ filter spectrum were defined as 52.111 to $60.319 \mathrm{keV}$. ENDBIB

COMMON

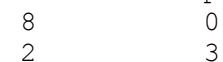

EN-MIN EN-MAX

$\mathrm{EV} \quad \mathrm{MEV}$

1.e-5 20

ENDCOMMON 30

DATA 201201

E

KEV ARB-UNITS

$40.5499 \quad .318100 \mathrm{E}-01$

$40.6795 \quad .370900 \mathrm{E}-01$

$61.5046 \quad .689100 \mathrm{E}-01$

$61.5322 \quad .474500 \mathrm{E}-01$

ENDDATA $\quad 1203$

ENDSUBENT $\quad 1220 \quad 0$

SUBENT $\quad 3223800320140507$

BIB 11

$\begin{array}{lcc}\text { REACTION } & (92-\mathrm{U}-235(\mathrm{~N}, \mathrm{X}) & 0-\mathrm{NN}-1, \mathrm{DE}, \mathrm{SPA} / \mathrm{REL}, \mathrm{EXP}) \\ \text { ENDBIB } & 1 & 0\end{array}$

ENDBIB

COMMON

EN-MIN

EV

1.e-5

ENDCOMMON

DATA

$\mathrm{E}$

39.9696

40.0953

69.8826

70.0083

ENDDATA

ENDSUBENT

SUBENT

BIB

$\begin{array}{ll}1 & 0 \\ 2 & 3\end{array}$

REACTION

EN-MAX

$\mathrm{MEV}$

20 .

$\begin{array}{rr}3 & 0 \\ 3 & 240\end{array}$

\section{3}

3223824

3223825

3223827

3223829

$\begin{array}{lll}32238 & 2 & 11\end{array}$

$32238 \quad 212$

32238213

32238214

32238215

32238216

32238217

32238218

32238219

32238220

32238221

STATUS (DEP, 32238002) Calculated neutron spectrum after filter

(DEP, 32238003) Experimental neutron spectrum after filter

(DEP, 32238005) Scattered neutron spectrum at the angle 15 ADEG (55 keV) calculated by the MCNP 4C code

(DEP, 32238006) Scattered neutron spectrum at the angle 20 ADEG (52 keV) calculated by the MCNP $4 \mathrm{C}$ code

(DEP, 32238007) Scattered neutron spectrum at the angle 25 ADEG (48.8 keV) calculated by the MCNP $4 \mathrm{C}$ code

COMMENT Correction connected with existence in the neutron scattered spectrum on CH2 neutrons scattered on carbon was done. A correction on the self-shielded effect was not be done for the measured values of the total cross sections of 52Cr.

The rough estimation, done by the MCNP 4C code calc., shown that the difference between the total cross sections at these energies and the observed self-shielded cross sections may rich 2-6\%.

ERR-ANALYS Total error includes: 


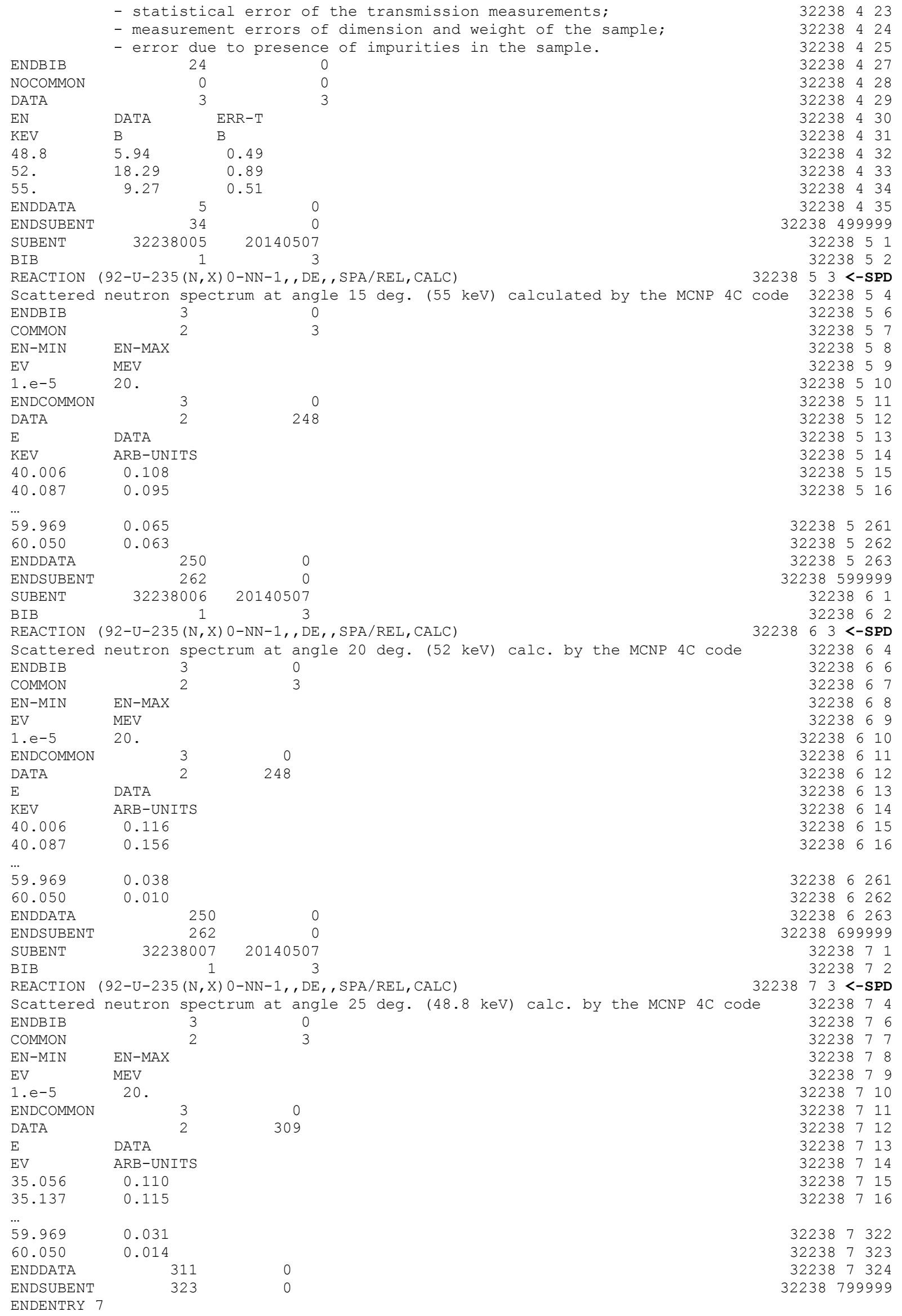




\subsection{Nuclear astrophysics data. Calculations of nuclear astrophysics and californium neutron cross section uncertainties using ENDF/B-VII.1, JEFF-3.1.2, JENDL-4.0 and low-fidelity covariances, B. Pritychenko}

Nuclear astrophysics and californium fission neutron spectrum averaged cross sections and their uncertainties for ENDF materials have been calculated. Absolute values were deduced with Maxwellian and Mannhart spectra, while uncertainties are based on ENDF/B-VII.1, JEFF-3.1.2, JENDL-4.0 and Low-Fidelity covariances. These quantities are compared with available data, independent benchmarks, EXFOR library, and analyzed for a wide range of cases. Recommendations for neutron cross section covariances are given and implications are discussed. These findings are published in Nucl. Data Sheets 123, 119 (2015).

\subsection{Structure of software on graphic data processing for the EXFOR data library, G. Pikulina, S.Taova, S. Dunaeva}

The previous version of InpGraph was designed more than 10 years ago. It was developed for our internal needs only. The main advantage of this version is a special processing procedure that provides compilation of image data of old images into EXFOR format. But the old version of InpGraph demands additional training of users as a strict order of digitizing operations is needed. This fact decreases the number of its potential users.

Nowadays the user's interface requirements have radically changed. So, we have decided to follow modern trends and create a user friendly interface.

The main idea was to design an intuitively understandable interface with the convenient tools for data digitizing. We tried to implement an approach of "identical user's reactions on identical user's actions".

Also we decided to use Wizard technology as an additional helper function for step instructions and hints during digitizing.

We implemented a selection of possible values from lists, automatic searching and automatic input, automatic checking on the input stage to minimize manual data input volume and to decrease possible error quantities.

This work was taken up two years ago.

We have analyzed different digitizing software (GetData Graph Digitizer, Graph2Digit, G3Date, Grafula) including GSYS and GDgraph.

We took into account the experience of the previous version use, feedbacks and proposals of the users.

We developed a flexible structure of InpGraph, new version and its internal data. Improvement and modification of our software are simpler for implementation now.

An algorithm of image processing for the EXFOR data base is implemented as a sequence of the following steps:

1. Import image into the program environment;

2. Edit the image if it is necessary;

3. Input service information as the EXFOR format demands;

4. Set axes, their names, units, directions;

5. Digitize data curves;

6. Process data and obtain physical data values;

7. Save compiled data in the EXFOR file. 
The InpGraph structure makes it possible to return at any digitizing stage and then edit the input data. This version of InpGraph does not require a strict order of operations.

We kept all advantages of the previous version of InpGraph in the new one:

- $\quad$ special math software compiles image data form old sources of low quality;

- digitizing and quantization errors are calculated;

- check of scale correctness is provided at the stage of data input and while creating the EXFOR file;

- traditional lens with separate points division is used for digitization:

- consequent creation of service files (AXS, SRC) with a possibility of their correction is supported;

- EXFOR-oriented data treatment including EXFOR format of the output file is implemented.

Summary of the new features of InpGraph:

- Operation of the initial data image loading is implemented in three ways: open any image format file, paste an image from clipboard or capture a part of screen.

- Input of service information has been optimized: EXFOR Dictionaries are used now.

- Procedure of data digitizing has been modified: automatic marking of axes has been implemented, editing of point positions and using of different colors and markers has been provided.

- Strict order of digitization is optional now. User can add any amount of abscissa and ordinate axes at any digitizing stage. Every axis has its own name. While digitizing curves, the user should select axes for every curve from the list available.

- Results of digitizing are stored in files with EXF extension. Service files with the extensions AXS, SRC are also created during compilation. Special edit windows are provided to make corrections (if necessary) in these files.

Thus, the new InpGraph version has all the advantages of the old one. We have tried to make it more convenient for the users. Now we are presenting the beta-version of InpGraph 3.0. Feedback and proposals from users is welcome and will all be taken into account. We are going to continue this development.

\subsection{Introduction to the digitization software GDgraph, Guochang Chen (Yongli Jin, Jimin Wang, CNDC, China)}

\section{Introduction}

GDgraph is a software for digitization. Since 1997, CNDC has been devoted to develop a software for digitization. The first version of digitization software GDGraph was developed and released in 2000 using VC++ language. Five years later, we collected much feedback information on update and bugs of this software. The $2^{\text {nd }}$ version of GDGraph software was released at 2006, in which the whole software was re-written using a Perl computer language to obtain more comfortable conditions for programming and updating. The version 3.0, 4.0 and 5.0 of GDGraph was released in 2011, 2012 and 2013, respectively.

\section{Main feature of GDGraph5.0}

(1) Operating system: WindowsXP or the later version of Windows.

(2) Intuitive and light GUI: Provides Chinese and English version GUI.

(3) Supports image format: such as PNG, GIF, BMP and JPEG etc.

(4) The image can be automatically fit to the GUI windowwith zoom-in or zoom-out manually together 
with the digitizing $\mathrm{X}, \mathrm{Y}$ axis.

(5) Allows to rotate the image and set a rotation angle with degree unit.

(6) The maximum digitizing data group number is three, and the colour, size and shape of each group can be defined by user using "Settings" function.

(7) Randomly adds the digitizing point and move it by mouse or cursor keys.

(8) Output data can be saved as a data file or at clipboard.

(9) Import data function enables to reuse the former digitizing data or compare with other data group easily.

(10) X, Y axes: Select or set a unit for X, Y data by user is available. Allows to digitize X, Y error with symmetry or asymmetry mode and move it using mouse or cursor keys, and set a fix value with relative $(\%)$ or absolute mode.

(11) Magnifying glass function: magnifies the local area of the image, and the window size can be set from $200 \%$ to $800 \%$ and be moved by mouse. The partial image in the magnifying glass window can be magnified by 2 or 4 times.

(12) Setting the colour, size and shape of digitizing point, the background with or without gridding lines, output digitizing numerical data format is available.

(13) Project function: It is used to save an image, digitizing results with other settings as a project file *.GDP for checking and modification in the future.

(14) Remark function is applied to keep some marks and memo text for checking, modification and memory by user.

\section{Basic Functions of GDGraph5.0}

\subsection{Loading an image file}

There have been some options to load an image. One is using "Load Graph File" from the "File" menu in the menu bar. Select an image file (as PNG, GIF, BMP or JPEG etc.) from a file dialog box in a new window and load the image with original size as default. Another way is to directly copy an image using clipboard from other file such as MS Word, PDF, etc. If an image file is successfully loaded, the image is displayed on the main panel as shown in Fig. 1. It is allowed to rotate with an setting angle, zoom in, zoom out, auto fit to the GUI window and revert the image size.

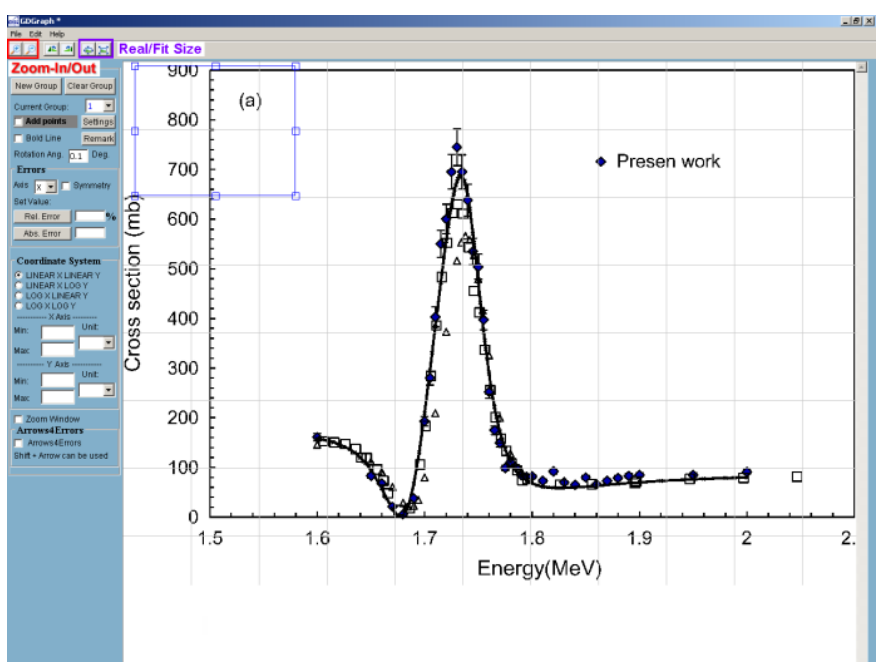

Fig. 1: An image loads on the main panel. 


\subsection{Setting axes}

Use cross lines to set the $\mathrm{X}-\mathrm{Y}$ axis, and adjust the square symbols of the starting, middle and ending positions of X-Y axis to fit the image one. Then select the X-Y axis type as Linear-Linear, Linear-Log, Log-Linear or Log-Log. According to the cross line positions, fill in the starting and ending value of $\mathrm{X}$ $\mathrm{Y}$ axes, and select or fill in units for X-Y axes at "Coordinate System" in "Control Panel" for identifying the digitizing data in the output data file, respectively. When we set or adjust the positions of axis, there exists an orthogonal frame to assist confirmation of the position of axes. When you finish setting the axis, you will see a window as shown in Fig. 2.

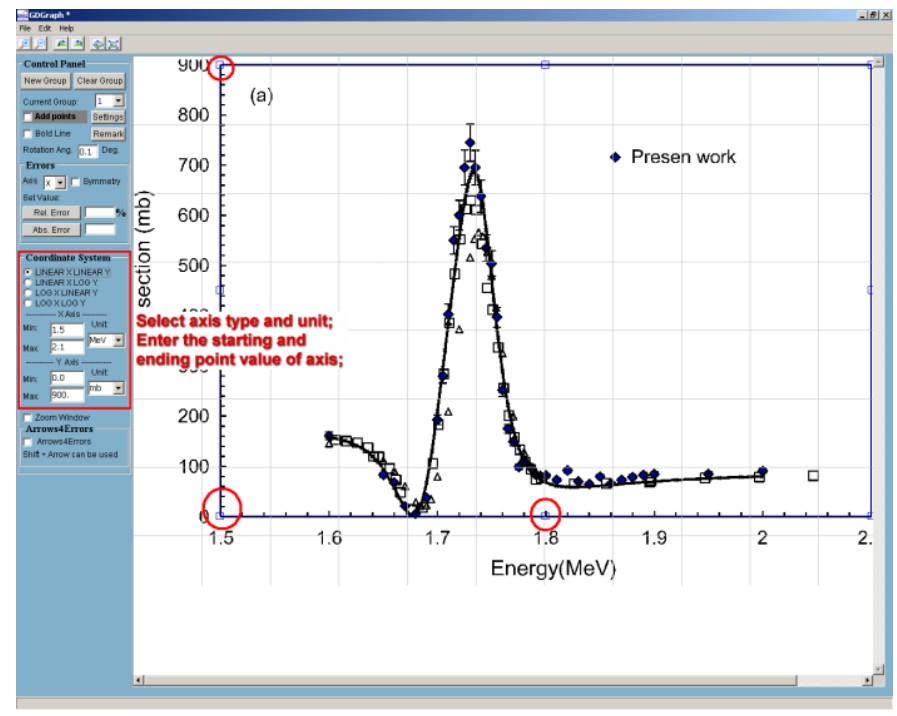

Fig. 2: Window after setting axes with squares.

\subsection{Digitizing the data and their uncertainties}

Activate the check box "Add points" to start digitization process. If you need to digitize more than one group points, please select which group you want to digitize or modify the original digitizing results. If you click on the image in the data input mode, a digitizing data point is added on the image. Continue to click the image until all the data points are added. When you finish adding the data points, you will see a window as shown in part (a) in Fig. 3.

The function of digitizing data point error is available with asymmetric or symmetric now. First of all, disable the "Add points" mode. Then, to select each error mode for X/Y with asymmetric or symmetric. The default error mode of $\mathrm{X} / \mathrm{Y}$ is asymmetric. To set a symmetric error for $\mathrm{X}$ or $\mathrm{Y}$, first select $\mathrm{X}$-axis or Y-axis at "Axis" list box in "Errors" part, then click "Symmetric" check box. After that, click a data point to activate it which will make 4 red square symbols appear around it. In this mode, move data point by mouse or cursor keys or set a fix value as X-Y error. The left and right square symbols represent X-Err-/X-Err+, and the bottom and top symbols represent Y-Err-/Y-Err+. If you obtain the information of $\mathrm{X}-\mathrm{Y}$ uncertainty from paper or other data sources, you can directly fill in a fixed value as $\mathrm{X}$-Y uncertainty with relative (\%, in percent) or absolute mode. You can directly use the mouse to pull one of four red squares to obtain X-Y error. On the other hand, you can apply "Arrows4Errors" function using cursor keys to move one of four red squares to proper position. After inputting errors, you will see a window as shown in part (b) of the Fig. 3. After digitizing one point, the "Pageup" or "Pagedown" key can be used to activate the previous or next data point. 


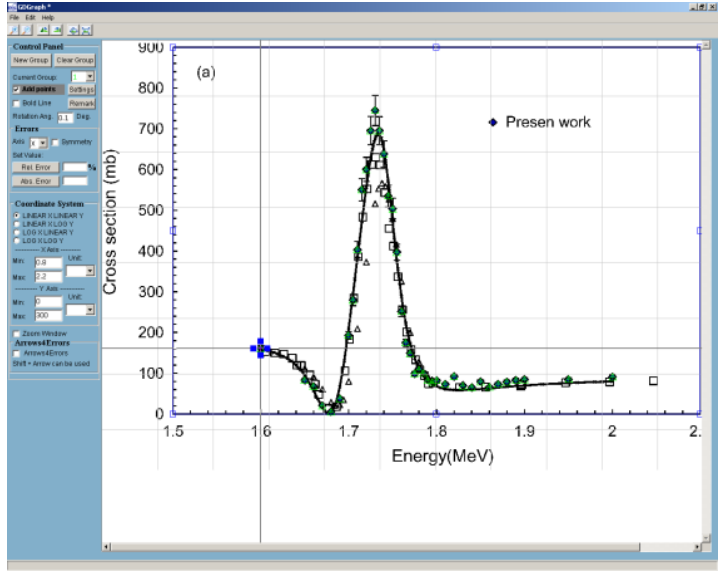

(a) Reading the data points

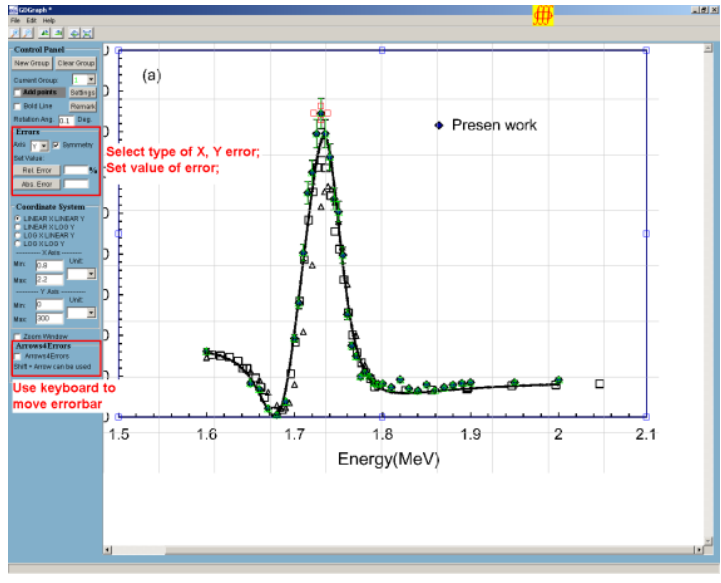

(b) Reading the data errors

Fig. 3: Window after reading the data points and errors.

\subsection{Outputting the digitizing result}

Select "Save Data File" from the "File" menu or directly use "Ctrl+C" to copy all digitizing results to clipboard and paste to other applications. The output data are in exponential or floating formats, and the number of digits can be set using the "Settings" function. Each data can be set as 11 columns to fit EXFOR format requirements. The output file contains the information of each group No., number of data points, name of each column and digitizing data. Each group output contains X, Y, Y-Err+, Y-Err-, X-Err-, and X-Err+ as shown in Fig. 4.

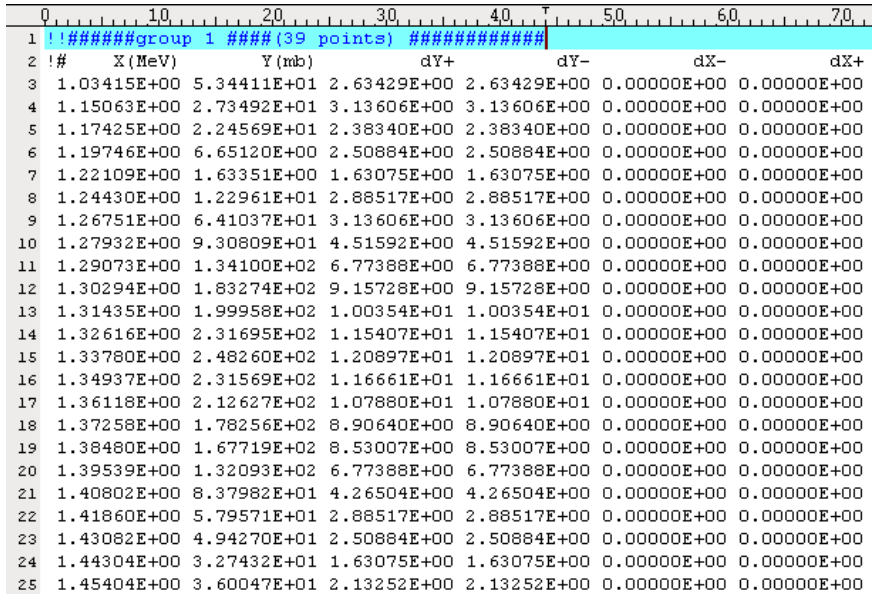

Fig. 4: An example of outputting numerical data file.

\section{Conclusion}

Since 1997, the digitization software GDgraph has been developed to fit the requirements of evaluation, measurement and EXFOR compilation. From the old software to the present version 5.0, GDgraph does mainly fit the requirements, although some modifications and additions of new functions are needed. 
2.12. Status of the compiled Neutron Spectra in EXFOR. Summary of discussions held at the Workshop and further developments, S. Simakov, N. Otuka, V. Semkova, V. Zerkin

\section{History}

The issue of compilation of Neutron Spectra in EXFOR was initially addressed at the IAEA Consultants' Meeting on "Neutron Sources Spectra for EXFOR” (13- 15 April 2011, IAEA), see:

- Summary Report INDC(NDS)-0590

- Presentations: https://www-nds.iaea.org/index-meeting-crp/CM-2011_web/.

\section{Current status of EXFOR}

NDS has searched the EXFOR database for Entries with Neutron and Photon Source Spectra information (energy distribution) which are collected under the keyword INC-SPECT.

The non-monoenergetic neutron sources are used for the measurements of Spectrum Averaged cross sections (SPA), fission yields and other physical quantities. This information is coded in the REACTION string, the numerical data are compiled in block DATA in the same Entry.

The results of search are summarised in Table 1 (around 17 Entries were found with the source energy distribution in INC-SPECT) and in Table 2 (no energy spectra, however with some additional information about neutron source).

Table 1. Entries with the neutron source energy distribution after keyword INC-SPECT.

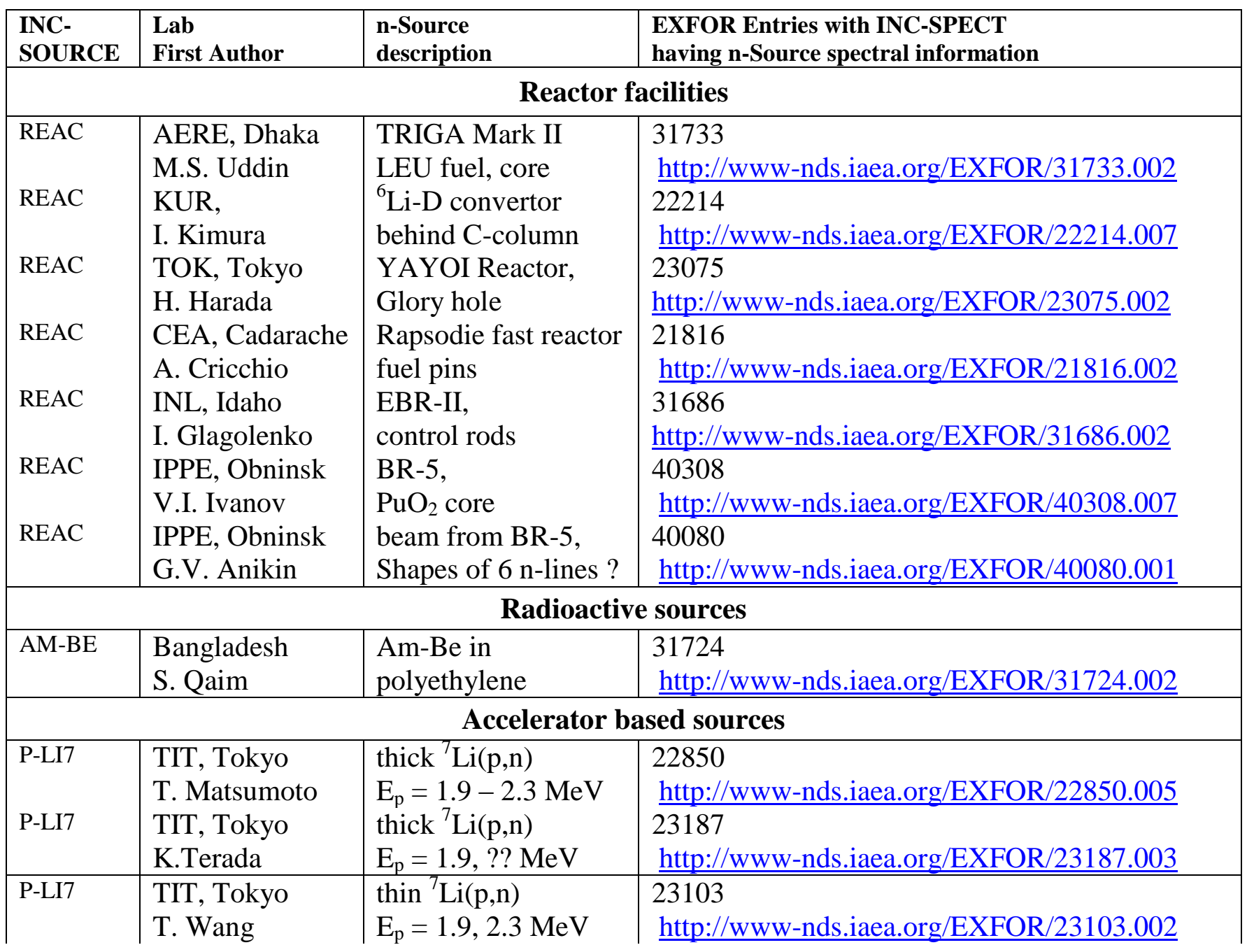




\begin{tabular}{|c|c|c|c|}
\hline $\begin{array}{l}\text { INC- } \\
\text { SOURCE }\end{array}$ & $\begin{array}{l}\text { Lab } \\
\text { First Author }\end{array}$ & $\begin{array}{l}\text { n-Source } \\
\text { description }\end{array}$ & $\begin{array}{l}\text { EXFOR Entries with INC-SPECT } \\
\text { having n-Source spectral information }\end{array}$ \\
\hline \multirow[t]{2}{*}{ P-LI7 } & Manipal & thin ${ }^{7} \operatorname{Li}(p, n)$ & 33033 \\
\hline & H. Naik & $\mathrm{E}_{\mathrm{p}}=5.6 \mathrm{MeV}$ & http://www-nds.iaea.org/EXFOR/33033.004 \\
\hline \multirow[t]{4}{*}{ P-LI7 } & KFK, Karlsruhe & thick ${ }^{7} \operatorname{Li}(p, n)$ & 01963 \\
\hline & F. Kaeppeler & & http://www-nds.iaea.org/EXFOR/O1963.002 \\
\hline & & & $\begin{array}{l}\text { this source was used to measure many }(\mathrm{n}, \gamma) \text { SPA, } \\
\text { e.g. http://www-nds.iaea.org/EXFOR/22996.003 }\end{array}$ \\
\hline & & & (link to O1963 should be included ?) \\
\hline \multirow[t]{2}{*}{ P-LI7 } & TSL, Uppsala & thin ${ }^{7} \operatorname{Li}(p, n)$ & 23129 \\
\hline & R. Bevilacqua & $\mathrm{E}_{\mathrm{p}}=179 \mathrm{MeV}$ & $\frac{\text { http://www-nds.iaea.org/EXFOR/23129.002 }}{\text { (should be comp. as separated p-Li spectrum ?) }}$ \\
\hline \multirow[t]{2}{*}{ P-BE9 } & WERC, Japan & $\mathrm{Be}(\mathrm{p}, \mathrm{xn})$ & 23238 \\
\hline & M.S. Uddin & $\mathrm{E}_{\mathrm{p}}=7.7 \mathrm{MeV}$ & $\frac{\text { http://www-nds.iaea.org/EXFOR/23238.002 }}{\text { (4 energy groups flux is given) }}$ \\
\hline \multirow[t]{2}{*}{ D-BE9 } & ANL & thick ${ }^{9} \mathrm{Be}(\mathrm{d}, \mathrm{xn})$ & 21857 \\
\hline & S. Liskien & $\mathrm{E}_{\mathrm{d}}=7 \mathrm{MeV}$ & http://www-nds.iaea.org/EXFOR/21857.002 \\
\hline \multirow[t]{3}{*}{ SPALL } & JINR, Dubna & $\mathrm{Pb}+\mathrm{U}$ blanket & 41529 \\
\hline & C. Bhatia & $\mathrm{E}_{\mathrm{d}}=1.6 \mathrm{GeV}$ & $\frac{\text { http://www-nds.iaea.org/EXFOR/41529.002 }}{41565}$ \\
\hline & & & http://www-nds.iaea.org/EXFOR/41565.002 \\
\hline \multirow{2}{*}{$\begin{array}{l}D-D \\
D-T\end{array}$} & FNG, Frascati & solid TiT, $D$ targets & 23127 \\
\hline & M. Pillon & $E_{d}=0.3 \mathrm{MeV}$ & $\frac{\text { http://www-nds.iaea.org/EXFOR/23127.002 }}{\text { (n-spectra is available - has to be compiled) }}$ \\
\hline
\end{tabular}

Table 2. Entries which do not have source energy distribution in INC-SPECT, however provide some numerical information about neutron filed.

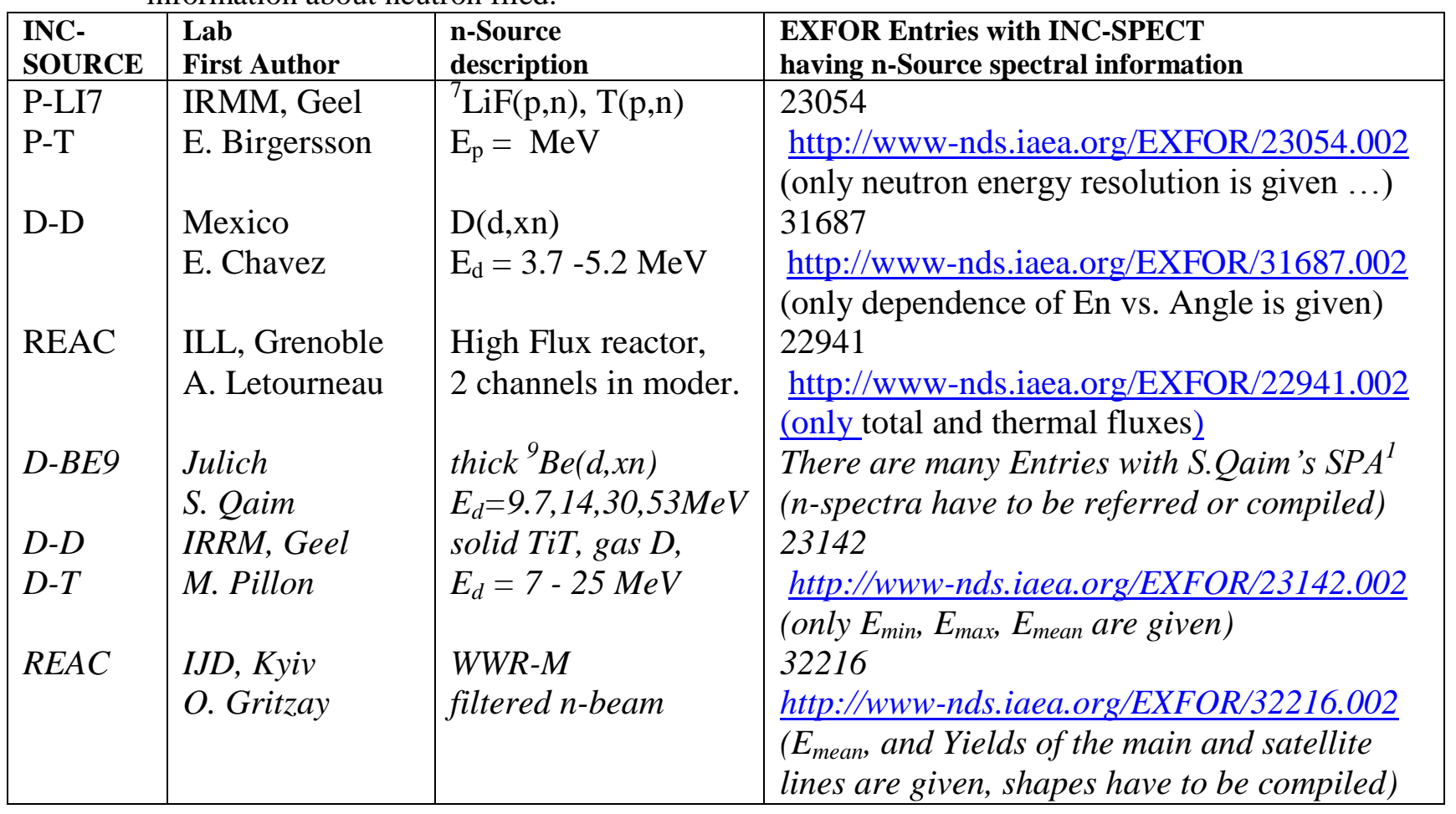

Comments to Tables 1 and 2: italic font-incident spectra were found and compiled after Workshop. 
Other Entries which have some information on the incident spectrum but do not contain energy distribution in INC-SPECT:

11467; 20139; 20436; 20534; 20735; 21812; 22007; 22089; 22105; 22340; 22392; 22658; 22661; 22748; 22794; 22837; 22838; 22858; 22882; 22903; 23027; 23067; 23078; 23105; 23222; 40063; 40476; 40924; C0228; C1516; G0002; M0536; O0291.

\section{Progress of work on inclusion of Neutron Spectra in EXFOR (after Workshop)}

The spectrum averaged cross sections measured by A. Zvonarev at the fast reactor assembly BR-1 (IPPE) were compiled early in $\underline{41068}$. After the workshop this Entry was updated by CJD:

- 14 group energy spectrum from the authors' publication was added under INC-SPECT,

- reference to ICSBEP( https://www.oecd-nea.org/science/wpncs/icsbep/) was added where this assembly (including the MCNP deck for the spectrum calculation) is described as a Benchmark FUND-IPPE-FR-MULT-RRR-001.

Several Incident Neutron Spectra (Figs. 1 and 2) were received from the authors and will be included in EXFOR:

- FNG facility at Frascati, D-D and D-T n-sources (M. Pillon), Entry 23127;

- D-Be n-sources at FZJ Julich (S. Qaim et al.). The overview of spectra used in his measurements see in INDC(NDS)-0590, p. 35 and the summary prepared by NDS see in Table 3.

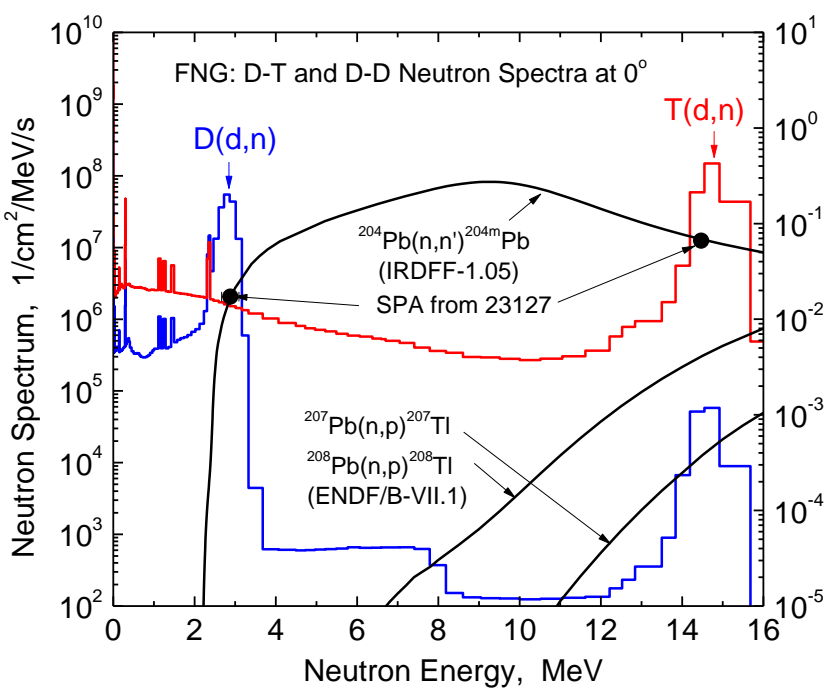

Fig. 1. Neutron spectra from D-T and D-D sources received in Nov 2014 from M. Pillon (175 groups presentation).

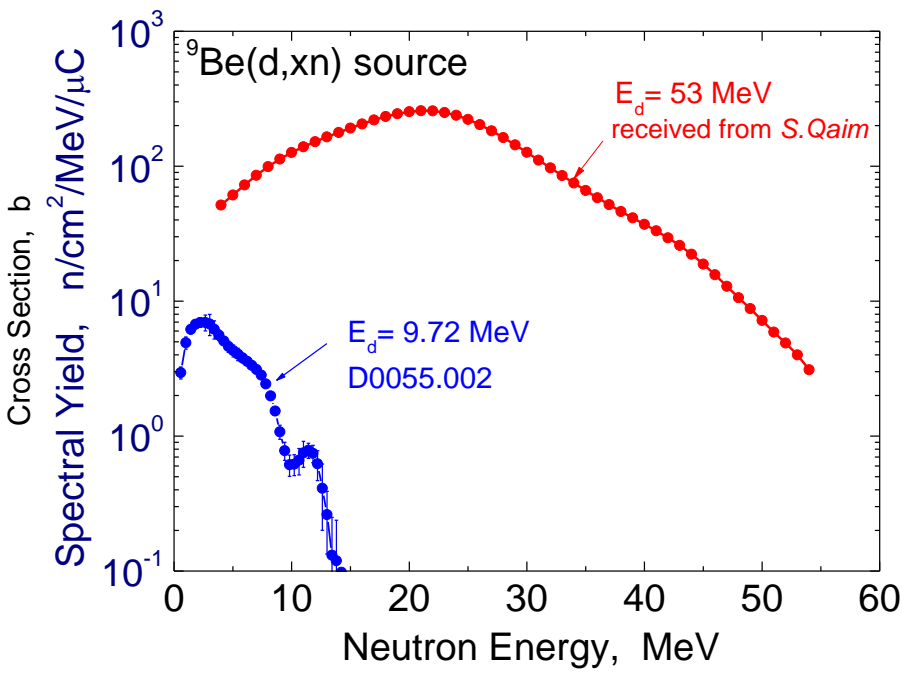

Fig. 2. Neutron spectra from D-Be sources received from S. Qaim et al. at 9.7 and $53 \mathrm{MeV}$ (51 points). 
Table 3. Information for the $\mathrm{d}(\mathrm{Be})$ neutron spectra applied for the spectrum average cross sections measurements performed at Institut fur Nuklearchemie, Forschungszentrum Julich GmbH, D-52425 Julich, Germany and corresponding EXFOR compilations.

\begin{tabular}{|c|c|c|c|c|c|}
\hline Reference & Ed, MeV & $\begin{array}{l}\text { n-Spectrum } \\
\text { Data / Units } \\
\end{array}$ & $\begin{array}{c}\text { Incident spectrum } \\
\text { additional information }\end{array}$ & EXFOR Entry & $\begin{array}{c}\text { How n-Spectra are } \\
\text { compiled now }\end{array}$ \\
\hline NP/A,100,537,1967 & "53.8 & $\begin{array}{l}\text { Table } \\
\mathrm{n} /(\mu \mathrm{C} \mathrm{MeV} \text { sr })\end{array}$ & & $\begin{array}{l}\text { O1924 } \\
\text { http://www-nds.iaea.org/EXFOR/O1924.002 }\end{array}$ & $\begin{array}{l}\text { REACTION } \\
\text { (4-BE-9(D,X)0-NN- } \\
\text { „TTY/PY/DA/DE) }\end{array}$ \\
\hline NP/A,329,63,1979 & 53.8 & $\begin{array}{l}\text { Text } \\
\mathrm{n} /(\mu \mathrm{C} \mathrm{MeV} \mathrm{sr})\end{array}$ & $\begin{array}{l}\text { Adopted from NP/A,100,537,1967 } \\
\text { and Phys.Med.Biol.20(1975)235 } \\
\text { Num. data provided by S.M Qaim }\end{array}$ & $\begin{array}{l}21009 \\
\text { http://www-nds.iaea.org/EXFOR/21009.003 }\end{array}$ & $\begin{array}{l}\text { EN-MEAN = 22.5MEV } \\
\text { EN-RSL-FW }=15.8 \mathrm{MEV}\end{array}$ \\
\hline RCA,62,107,1993 & 53.8 & $\begin{array}{l}\text { Text } \\
\mathrm{n} /(\mu \mathrm{C} \mathrm{MeV} \mathrm{sr})\end{array}$ & $\begin{array}{l}\text { Adopted from NP/A,100,537,1967 } \\
\text { and Phys.Med.Biol.20(1975)235 } \\
\text { Num. data provided by S.M Qaim }\end{array}$ & $\begin{array}{l}22708 \\
\text { http://www-nds.iaea.org/EXFOR/22708.002 } \\
\text { Data compiled without SF8=SPA }\end{array}$ & $\mathrm{EN}=53 \mathrm{MEV}$ \\
\hline $\mathrm{NP} / \mathrm{A}, 410,421,1983$ & 53.8 & $\begin{array}{l}\text { Text } \\
\mathrm{n} /(\mu \mathrm{C} \mathrm{MeV} \mathrm{sr})\end{array}$ & $\begin{array}{l}\text { Adopted from NP/A,100,537,1967 } \\
\text { and Phys.Med.Biol.20(1975)235 } \\
\text { Num. data provided by S.M Qaim }\end{array}$ & $\begin{array}{l}21916 \\
\text { http://www-nds.iaea.org/EXFOR/21916 }\end{array}$ & $\begin{array}{l}\text { EN = 22.5MEV } \\
\text { EN-RSL-HW = 7.9 MEV }\end{array}$ \\
\hline JIN,36,3639,1974 & 53.8 & $\begin{array}{l}\text { Figure } \\
\mathrm{n} /(\mu \mathrm{C} \mathrm{MeV} \mathrm{sr})\end{array}$ & $\begin{array}{l}\text { Adopted from NP/A,100,537,1967 } \\
\text { and Phys.Med.Biol.20(1975)235 } \\
\text { Num. data provided by S.M Qaim }\end{array}$ & $\begin{array}{l}20524 \\
\text { http://www-nds.iaea.org/EXFOR/20524 }\end{array}$ & EN-APRX $=22.5 \mathrm{MeV}$ \\
\hline ARI,30,3,1979 & 53.8 & Text & $\begin{array}{l}\text { From NP/A, } 100,537,1967 \\
\text { Num. data provided by S.M Qaim }\end{array}$ & $\begin{array}{l}21878 \\
\text { http://www-nds.iaea.org/EXFOR/21878 }\end{array}$ & $\begin{array}{l}\text { EN = 22.5MEV } \\
\text { EN-RSL-HW = } 7.9 \mathrm{MEV}\end{array}$ \\
\hline NP/A,295,150,1978 & 53.8 & Text & $\begin{array}{l}\text { From NP/A,100,537,1967 } \\
\text { Num. data provided by S.M Qaim }\end{array}$ & $\begin{array}{l}20840 \\
\text { http://www-nds.iaea.org/EXFOR/20840 }\end{array}$ & EN-DUMMY $=22.5 \mathrm{MEV}$ \\
\hline NSE,91,162,1985 & $\begin{array}{l}17.5,20 \\
22.5,25 \\
27.530\end{array}$ & $\begin{array}{l}\text { Tables } \\
\mathrm{n} /\left(\mathrm{cm}^{2} \mathrm{~s} \mathrm{MeV}\right)\end{array}$ & & $\begin{array}{l}21988 \text { (Cross sections determined from the } \\
\text { SPA measured at given d(Be) spectra) } \\
\text { http://www-nds.iaea.org/EXFOR/21988 }\end{array}$ & no information given \\
\hline $\begin{array}{l}\text { 91JUELIC, }, 297,199 \\
1\end{array}$ & $\begin{array}{l}20 \text { and } \\
25\end{array}$ & Text & From NSE,91,162,1985 & $\begin{array}{l}22444 \\
\text { http://www-nds.iaea.org/EXFOR/22444 }\end{array}$ & EN-MIN = 2 MEV \\
\hline NP/A,423,130,1984 & 30 & $\begin{array}{l}\text { Figure } \\
\mathrm{n} /(\mathrm{sr} \mu \mathrm{Cs} \mathrm{MeV})\end{array}$ & & $\begin{array}{l}21934 \\
\text { http://www-nds.iaea.org/EXFOR/21934 }\end{array}$ & EN-DUMMY $12 \mathrm{MeV}$ \\
\hline $\begin{array}{l}\text { 76GARMIS,,589,1 } \\
97606\end{array}$ & 30 & $\begin{array}{l}\text { Figure } \\
\mathrm{n} /(\mathrm{sr} \mu \mathrm{C} \text { s } \mathrm{MeV})\end{array}$ & & $\begin{array}{l}20721 \\
\text { http://www-nds.iaea.org/EXFOR/20721 }\end{array}$ & EN-DUMMY $=11.5 \mathrm{MEV}$ \\
\hline $\begin{array}{l}\text { BNL-NCS- } \\
51245,539,1980\end{array}$ & 30 & $\begin{array}{l}\text { Figure } \\
\mathrm{n} /(\mathrm{sr} \mu \mathrm{A} s \mathrm{MeV})\end{array}$ & & $\begin{array}{l}21649 \\
\text { http://www-nds.iaea.org/EXFOR/21649 }\end{array}$ & EN-DUMMY $=20 \mathrm{MeV}$ \\
\hline RCA,51,49,1990 & 31 & $\begin{array}{l}\text { Figure } \\
\mathrm{cm}^{-1} \mathrm{~s}^{-1} \text { rel.scale }\end{array}$ & & $\begin{array}{l}30977 \\
\text { http://www-nds.iaea.org/EXFOR/30977 }\end{array}$ & EN-DUMMY $=10 \mathrm{MEV}$ \\
\hline
\end{tabular}




\begin{tabular}{|c|c|c|c|c|c|}
\hline Reference & Ed, MeV & $\begin{array}{l}\text { n-Spectrum } \\
\text { Data / Units }\end{array}$ & $\begin{array}{c}\text { Incident spectrum } \\
\text { additional information }\end{array}$ & EXFOR Entry & $\begin{array}{c}\text { How n-Spectra are } \\
\text { compiled now }\end{array}$ \\
\hline \multirow[t]{3}{*}{$\begin{array}{l}\text { NIM/A,404,373,19 } \\
98\end{array}$} & \multirow[t]{2}{*}{$\begin{array}{l}9.72 \\
\text { ATOMKI }\end{array}$} & $\begin{array}{l}\text { Figure } \\
\mathrm{n} /\left(\mathrm{cm}^{2} \mathrm{~s} \mathrm{MeV}\right)\end{array}$ & & $\begin{array}{l}\mathrm{d}(\mathrm{Be}) \text { spectrum compiled in D0055 } \\
\text { http://www-nds.iaea.org/EXFOR/D0055.002 }\end{array}$ & $\begin{array}{l}\text { REACTION } \\
\text { (4-BE-9(D,N)5-B- } \\
\text { 10,,TTY/MLT/DE,REL) }\end{array}$ \\
\hline & & & & $\begin{array}{l}\text { Data compiled in } 31495 \\
\text { http://www-nds.iaea.org/EXFOR/31495.016 } \\
\text { http://www-nds.iaea.org/EXFOR/31495.040 }\end{array}$ & EN-MEAN = $4.3 \mathrm{MEV}$ \\
\hline & $\begin{array}{l}13.55 \\
\text { Juelich }\end{array}$ & $\begin{array}{l}\text { Figure } \\
\text { arbitrary units }\end{array}$ & & & \\
\hline $\begin{array}{l}\text { ARI,64,717,2006 } \\
\text { RCA,92,183,2004 }\end{array}$ & 14 & $\begin{array}{l}\text { Figure } \\
\text { arbitrary units }\end{array}$ & From NIM/A,404(1998)373 & $\begin{array}{l}22857 \\
\text { http://www-nds.iaea.org/EXFOR/22857 }\end{array}$ & EN-DUMMY $=3 \mathrm{MeV}$ \\
\hline ARI,54,655,2001 & 14 & Text & From NIM/A,404(1998)373 & $\begin{array}{l}22664 \\
\text { http://www-nds.iaea.org/EXFOR/22664.011 }\end{array}$ & EN-MEAN $=13.6 \mathrm{MeV}$ \\
\hline $\begin{array}{l}\text { INDC(GER)- } \\
049,10,2003\end{array}$ & 14 & Text & From NIM/A,404(1998)373 & $\begin{array}{l}22832 \\
\text { http://www-nds.iaea.org/EXFOR/22832 }\end{array}$ & EN-MEAN $=14 \mathrm{MeV}$ \\
\hline
\end{tabular}




\section{Summary of the discussion at this Workshop.}

Following two Alternatives for the Neutron source compilation were considered (highlighted in red - new for EXFOR).

First Alternative: use the REACTION string for incident spectrum, i.e. create new special SubEntry to code the incident Spectrum as Reaction string:

REACTION (U-238-SRC(0,0),,DE,,SPD)

which will specify Spectrum for already existing SubEntry with reaction SPA cross section coded by proper spectrum code SF8 = MXA, EPI, FIS, FSR, BRA, SPA in REACTION (6-C-12(N,TOT) , , , ,SPA

Second Alternative: continue to use INC-SPECT for incident spectrum, i.e. store spectrum information (data, reference or link to file with spectrum) after keyword INC-SPECT [or extended keyword INC-SPECT(DE,...) for searching, plotting etc. ] as a free text (spectrum itself and how it was obtained), e.g.:

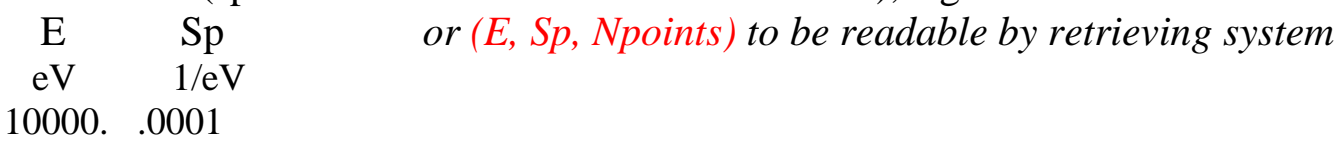

\subsection{EXFOR Web Editor, V. Zerkin}

A new project "Light EXFOR Web Editor" is presented, the current stage of implementation was demonstrated, the possible development is discussed. The idea of the project is to re-use existing software, such as: Web presentation of an EXFOR files as interactive tree $\mathrm{X} 4 \pm$ and Reference checker, and extend them by editing features. The Editor will operate on the user's side only in the Web browser; it could be used with and without Internet connection. For the moment, it is a "Pilot" project; plans and details of the project are not yet fully clarified and fixed.

\section{Summary of the discussions}

The NDS project "Light EXFOR Web Editor" was supported by NNDC (B. Pritychenko) and other participants as an alternative of EXFOR-Editor and software independent from: operating system, commercial system components, internal policy of organizations (of nuclear data centers), etc. 


\section{Summary of discussions and recommendations}

The workshop has facilitated the best software, EXFOR compilation practices, and facilitated exchange between the different NRDC centers. This exchange will provide an increase in compilation productivity and overall quality improvements of the EXFOR library. Several presentations have led to extensive discussions, and produced valuable suggestions that are listed below in chronological order.

1. Some comments on EXFOR compilations, N. Otuka:

1.1. Binary heavy ion case: both nuclei should have E-LVL1 and E-LVL2 tags. Compilers should not omit such information.

1.2. N. Otuka and O. Schwerer should clarify the difference between the alternative and interdependent results and update the manual.

1.3. Compilers are discouraged to use FLAG to distinguish the alternative results.

1.4. Compilers are recommended to delete unnecessary keywords from the deleted entries.

1.5. Compilers are encouraged to use concise free text statements.

1.6. Compilers should make important alterations more visible using the keyword HISTORY.

2. Compilations of beta-delayed neutron emission data. V. Semkova:

2.1. IAEA/Compilers should review a consistency of the old compilations with new rules for beta-delayed neutrons, and for TOF measurements.

2.2. Substantial problems should trigger the recompilation of existing entries.

3. EXFOR compilations for CIELO project. B. Pritychenko:

3.1. Compilers should follow the NRDC action A56, and assign a high priority for six CIELO materials UNOBT data compilations; perhaps deletion of "empty" subentries, and general cleaning of irrelevant data.

3.2. General revision of the updated entries by the whole network.

3.3. EXFOR compilations should be performed in close contacts with the evaluators, and experimentalists. Contacts with the CSEWG and other groups are encouraged.

3.4. Recent problems with EXFOR editor installation on Windows 7 triggered a request for a Web-based EXFOR editor that can be implemented using the platformindependent solutions by V. Zerkin. This, complementary, editor will provide an alternative route for non-Windows compilers.

3.5. Nuclear data community has requested the IAEA to produce two different Email distribution lists: EXFOR general and compilation-specific lists.

3.6. NNDC strongly supports the IAEA-led effort on electronic library creation. It can be a joint project between two organizations, and include all EXFOR and NSR publications. Copyrights restrictions will represent a certain challenge for this project.

3.7. Data transfer from EXFOR to NSR should proceed according to the NRDC action A84.

4. Results on the ${ }^{100} \mathrm{Mo}(\mathrm{p}, 2 \mathrm{n}){ }^{99 \mathrm{~m}} \mathrm{Tc}$ cross section measurements and possible systematic errors. S. Takacs:

4.1. Decay data are important in EXFOR compilations: compilers should contact authors if problems are found.

4.2. Recommended data: compilers can include author's recommendations in the compilation.

4.3. Compilers should be aware that systematic errors are present in the experimental data. 
4.4. S. Takacs \& N. Otuka should revisit the definition of yields, old entries on TTY, and propose corrections for reaction codes.

5. Kerma factors in EXFOR: actual status and missing published results. S. Simakov:

Compilers are encouraged to add 20 publications on Kerma factors, and revise 2 existing EXFOR entries 22507 and 22811.

6. Some problems of photonuclear data compilation and evaluation. V. Varlamov:

6.1. Compilers should be careful in partial and total photonuclear reaction definition due to possible contribution of protons in photoneutron reactions and vice versa of neutrons in photoproton reactions.

6.2. Users and evaluators should be very careful with photonuclear data because monochromatic gamma sources do not exist; this introduces additional systematic errors.

6.3. Many photonuclear data sets need to be reexamined.

7. Compilation of neutron data in the resolved resonance region measured by TOF method. Spectrometers' response function, V. Semkova:

ORELA data and resolution function should be recovered by the NNDC according to the NRDC action A36: B. Pritychenko.

8. Neutron source spectra format, O. Gritzay:

O. Gritzay should prepare a new proposal for neutron spectra compilations and distribute it among the NRDC members.

9. Nuclear astrophysics data. Calculations of nuclear astrophysics and californium neutron cross section uncertainties using ENDF/B-VII.1, JEFF-3.1.2, JENDL-4.0 and low-fidelity covariances, B. Pritychenko:

B. Pritychenko \& N. Otuka should generate a nuclear astrophysics priority list for the NRDC network based on the KADONIS stellar nucleosynthesis library and other sources.

10. Structure of software on graphic data processing for EXFOR data library, G. Pikulina:

- Software developers should make improvements to curve digitizers according to user's comments. This suggestion is applicable for all network digitizers.

- Compilers are encouraged to eliminate error analysis correction from EXFOR compilations, per S. Dunaeva suggestion.

11. Additional presentation on EXFOR software and editing tools, V. Zerkin:

- It will be highly-beneficial for all if the IAEA-EXFOR interface will provide a "Text Google Search" option.

- Workshop attendees strongly support and appreciate the effort on checking codes by V. Zerkin.

Finally, several EXFOR compilations were produced, and discussed by the workshop attendees before the workshop was adjourned. The workshop organizers and attendees will continue their work at home institutions until the next NRDC meeting. 


\section{Workshop on}

\section{Compilation for Experimental Nuclear Reaction Data Base EXFOR}

6 - 10 October 2014, Vienna, Austria

Meeting Room: M0E10

\section{AGENDA}

Monday, 6 October 2014

(Coffee breaks morning / afternoon as appropriate)

9:30 - 12:30

1.1 Welcome address

$10 \mathrm{~min}$

R. Forrest

1.2 Self-introduction

$15 \min$

All

1.3 Announcement

5 min

K. Nathani

1.4 Objectives of the workshop

$10 \mathrm{~min}$

V. Semkova

1.5 Some comments on EXFOR compilation.

$150 \mathrm{~min}$

N. Otsuka

\section{2:30 - 14:00 Lunch break}

\section{4:00 - 18:00}

1.6 Compilation of beta-delayed neutron emission data.

1.7 Compilation exercises on beta-delayed neutron emission data

$\begin{array}{ll}60 \mathrm{~min} & \text { V. Semkova } \\ 180 \mathrm{~min} & \text { All }\end{array}$

Tuesday, 7 October 2014

\section{9:00 - 13:00}

Review of the compilation exercise of $6^{\text {th }}$ October

$30 \min$

V. Semkova

2.1 EXFOR compilations for CIELO project

2.2 Results on the ${ }^{100} \mathrm{Mo}(\mathrm{p}, 2 \mathrm{n}){ }^{99 \mathrm{~m}} \mathrm{Tc}$ cross section

$60 \min$

N. Otsuka measurements and possible systematic errors.

$60 \mathrm{~min}$

B. Pritychenko Definition of radioisotope thick target yields.

2.3 Kerma factors in EXFOR: actual status and missing

$60 \mathrm{~min}$

S. Takacs published results.

\section{3:00 - 14:00 Lunch break}

14:00 - 18:00

2.4 Compilation exercises on charged particle-induced data and Kerma factors. 
9:00 - 13:00

Review of the compilation exercises of $7^{\text {th }}$ October

3.1 Some problems of photonuclear data compilation and evaluation.

3.2 Compilation of neutron data in resolved resonance region measured by TOF method. Spectrometers' response function.

3.3 Neutron source spectra format.

\section{3:00 - 14:00 Lunch break}

14:00 - 18:00

3.4 Compilation exercises on neutron-induced and photonuclear data.

\section{Thursday, 9 October 2014}

\section{9:00 - 13:00}

4.1 Nuclear astrophysics data. Calculations of nuclear astrophysics and californium neutron cross section uncertainties using ENDF/B-VII.1, JEFF-3.1.2, JENDL-4.0 and low-fidelity covariances.

4.2 Structure of software on graphic data processing for the EXFOR data library.

4.3 User's interface of a program on graphic data processing for the EXFOR data library: approaches, solutions, capabilities.

4.4 Introduction of digitization software GDgraph.

4.5 Digitization software GSYS.

4.6 Digitization capabilities of Origin 9.0.
$45 \min$

$45 \mathrm{~min}$

$45 \min$

$45 \min$

O. Gritzay

S. Takacs

N. Otsuka
S.P. Simakov

V. Varlamov

V. Semkova

$240 \mathrm{~min} \quad$ All

$60 \mathrm{~min}$

B. Pritychenko

$30 \min$

G. Pikulina

$30 \mathrm{~min}$

S. Taova

$30 \mathrm{~min}$

Chen Guochang

30 min

D. Ichinkhorloo

B.

Marcinkevicius

\section{3:00 - 14:00 Lunch break}

14:00 - 18:00

4.7 Digitization tools and compilation exercises on nuclear 240 astrophysics data.

Friday, 10 October 2014

9:00 -

5.1 Review of the compilation exercises of $8^{\text {th }}$ and $9^{\text {th }}$

B. Pritychenko

October

V. Varlamov

N. Otsuka

5.2 Discussions.

5.3 Closing of the meeting 


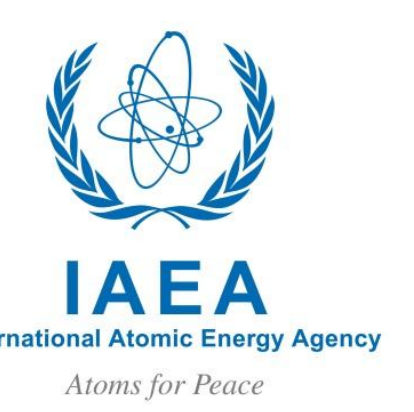

\section{LIST OF PARTICIPANTS}

\section{AUSTRIA}

Otto Schwerer

Gumpendorferstrasse 9/18

1060 Vienna

Tel.: +4315861351

Mobile: +43 6767755839

E-mail: otto.schwerer@aon.at

\section{HUNGARY}

Sandor Takacs

Institute of Nuclear Research

Hungarian Academy of Sciences

Bem ter $18 / \mathrm{c}$

H-4001 Debrecen

Tel.: +36 52509200

Fax: +36 52416181

E-mail: stakacs@atomki.hu

\section{KAZAKHSTAN}

Nurzat Kenzhebayev

Physical-Technical Department

Al-Farabi Kazakh National University

Room 319

Almaty 050022

Tel.: +7 7273773458

E-mail: nurzat89@mail.ru

\section{RUSSIAN FEDERATION}

Galina Pikulina

Russia Federal Nuclear Center

All Russia Scientific Research

Institute of Experimental Physics

607188, Sarov

Nizhnii Novgorod Region

Tel.: +7 8313027779

Fax: +7 8313045569

E-mail: pikulina@expd.vniief.ru

\section{CHINA}

Guochang Chen

China Nuclear Data Center

China Institute of Atomic Energy

P.O.Box 275-41

Beijing 102413

Tel.: +861069358604

Fax: +86 1069358119

E-mail: cgc@ciae.ac.cn

$$
\text { cgc_406961@yahoo.com }
$$

\section{JAPAN}

Dagvadorj Ichinkhorloo

Hokkaido University

Nuclear Research Data Center

Kita-ku, Kita-10, Nishi-8

Sapporo 060-0810

Tel.: +81 (11) 706-3818

Fax: +81 (11) 706-3724

E-mail: ichinkhorloo@nucl.sci.hokudai.ac.jp

\section{RUSSIAN FEDERATION}

Marina Mikhailiukova

Institute for Physics and Power Engineering

Bondarenko Sq. 1

Kaluga Region

249033 Obninsk

Tel.: +7 4843998779

Fax: +7 4843968225

E-mail: mmarina@ippe.ru

\section{RUSSIAN FEDERATION}

Sophiya Taova

Russian Federal Nuclear Center

All Russia Scientific Research Institute

of Experimental Physics

607188, Sarov

Nizhnii Novgorod Region

Tel.: +7 8313027779

Fax: +7 8313045569

E-mail: taova@expd.vniief.ru 
RUSSIAN FEDERATION

Vladimir Varlamov

Centre for PhotonuclearEksperimentov

Skobeltsyn Institute of Nuclear Physics

Lomonosov Moscow State University

119991 Moscow

Tel.: +7 4959393483

Fax: +7 4959390896

E-mail: varlamov@depni.sinp.msu.ru

vvvarlamov@gmail.com)

\section{UNITED STATES OF AMERICA}

Boris Pritychenko

National Nuclear Data Center

Brookhaven National Laboratory

Bldg 197D, P/O. Box 5000

Upton NY 11973-5000

Tel.: +1 631-344-5091

Fax: +1 631-344-2806

E-mail: pritychenko@bnl.gov

IAEA

Valentina Semkova (Scientific Secretary)

Nuclear Data Section

Division of Physical and Chemical Sciences

Tel.: +4312600 21727

Fax: +4312600721727

E-mail v.semkova@iaea.org

\section{IAEA}

Stanislav Simakov

Nuclear Data Section

Division of Physical and Chemical Sciences

Tel.: +4312600 21717

Fax: +4312600721717

E-mail: s.simakov@iaea.org

\section{UKRAINE}

Olena Gritzay

Ukrainian Nuclear Data Center

Institute for Nuclear Research

Prospekt Nauky 47

03680 Kyiv

Tel.: +380445253987

Fax: +380445254463

Email: ogritzay@kinr.kiev.ua
IAEA

Naohiko Otsuka

Nuclear Data Section

Division of Physical and Chemical Sciences

Tel.: +4312600 21715

Fax: +4312600721715

E-mail: n.otsuka@iaea.org

\section{IAEA}

Viktor Zerkin

Nuclear Data Section

Division of Physical and Chemical Sciences

Tel.: +431260021714

Fax: +4312600721714

E-mail: v.zerkin@iaea.org 

